\title{
The Impact of the Geometry of the Effective Propped Volume on the Economic Performance of Shale Gas Well Production
}

\author{
Andres Soage $^{1}\left(\mathbb{D}\right.$, Ruben Juanes ${ }^{2,3}(\mathbb{D})$, Ignasi Colominas ${ }^{1}(\mathbb{D})$ and Luis Cueto-Felgueroso ${ }^{4, *(\mathbb{D})}$ \\ 1 Group of Numerical Methods in Engineering, Universidadeda Coruña, Campus de Elviña, \\ 15071 A Coruña, Spain; a.soage@udc.es (A.S.); icolominas@udc.es (I.C.) \\ 2 Department of Civil and Environmental Engineering, Massachusetts Institute of Technology, \\ Cambridge, MA 02139, USA; juanes@mit.edu \\ 3 Department of Earth, Atmospheric and Planetary Sciences, Massachusetts Institute of Technology, \\ Cambridge, MA 02139, USA \\ 4 Department of Civil Engineering: Hydraulics, Energy and Environment, Universidad Politécnica de Madrid, \\ 28006 Madrid, Spain \\ * Correspondence: luis.cueto@upm.es
}

Citation: Soage, A.; Juanes, R.; Colominas, I.; Cueto-Felgueroso, L. The Impact of the Geometry of the Effective Propped Volume on the Economic Performance of Shale Gas Well Production. Energies 2021, 14, 2475. https://doi.org/10.3390/ en14092475

Academic Editor: Manoj Khandelwal

Received: 9 March 2021

Accepted: 19 April 2021

Published: 26 April 2021

Publisher's Note: MDPI stays neutral with regard to jurisdictional claims in published maps and institutional affiliations.

Copyright: (c) 2021 by the authors. Licensee MDPI, Basel, Switzerland. This article is an open access article distributed under the terms and conditions of the Creative Commons Attribution (CC BY) license (https:// creativecommons.org/licenses/by/ $4.0 /)$.

\begin{abstract}
We analyze the effect that the geometry of the Effective Propped Volume (EPV) has on the economic performance of hydrofractured multistage shale gas wells. We study the sensitivity of gas production to the EPV's geometry and we compare it with the sensitivity to other parameters whose relevance in the production of shale gas is well known: porosity, kerogen content and permeability induced in the Stimulated Recovery Volume (SRV). To understand these sensitivities, we develop a high-fidelity 3D numerical model of shale gas flow that allows determining both the Estimated Ultimate Recovery (EUR) of gas as well as analyzing the decline curves of gas production (DCA). We find that the geometry of the EPV plays an important role in the economic performance and gas production of shale wells. The relative contribution of EPV geometry is comparable to that of induced permeability of the SRV or formation porosity. Our results may lead to interesting technological developments in the oild and gas industry that improve economic efficiency in shale gas production.
\end{abstract}

Keywords: decline curve analysis (DCA); geometry effective propped volume (EPV); economic performance shale gas; ellipsoidal hydrofractures; shale gas 3D production model

\section{Introduction}

Fossil fuels will likely remain a critical energy source for our society at least until 2050 [1]. However, the need to reduce the emission of greenhouse gases is driving a transition from heavier fuels to lighter and less polluting ones [2]. In particular, "dry" gas or methane is the cleanest fossil energy source, and is poised to play a central role in the transition to a decarbonized energy system [3]. Unconventional gas resources, in particular methane produced from hydrofractured shale formations, continue to generate controversy but are undoubtedly a high potential methane source [4], abundant and widely distributed throughout the planet [5-7]. The systemic challenge of shale gas exploitation is that there is a high variability in the production capacity of the wells and therefore in their economic efficiency $[4,8,9]$. There is a large number of wells that are not productive and therefore not profitable, while the more productive wells are few but with spectacular gas recovery rates and economic efficiency [10]. Thus, there are studies that indicate that widely exploited formations such as Barnett in the USA yield surprising data. In this play, since 1997, 20\% of the most productive wells have contributed $40 \%$ of the gas drawn, while the least productive $20 \%$ has not even reached $5 \%$ of the whole production [11]. In many of the cases, these non-productive wells are reconverted to productive wells through refracturing, which suggests that the location and completion of the well were appropriate, but the hydrofracturing was not effective [12]. This raises the question of what 
geological settings and technological designs determine the profitability of hydrofractured shale wells.

Hydraulic fracturing produces a network of fractures in the shale gas formation that increases the effective permeability of the formation by several orders of magnitude. The injection of fracturing fluid and proppants enhances the permeability of the host rock by opening new or preexisting cracks. These processes are called hydrofracturing [13,14]. According to microseismic imaging a shale gas formation subject to hydraulic fracturing develops damage zones or fracture volumes, Effective Propped Volume (EPV), with a fundamentally ellipsoidal geometry [15-25]. Furthermore, externally to this ellipsoidal zone, a fracturing zone called Stimulated Recovery Volume (SRV) is produced, generally represented by a prism in the technical and scientific literature [26-28]. In the SRV there is also an increase in permeability but not as prominent as in the hydrofractured zone.

Modeling studies of gas production from hydrofractured shale formations are based on suitable physical hypothesis regarding the state of the gas (adsorbed, free, dissolved) [26-29]. Some studies consider the inclusion of slippage effects (Klinkenberg effect) [30] and/or inertial effects (Forchheimer effect) [31]. They also analyze the petrological parameters of the shale formation, especially the sensitivity of the production to the permeability induced by the hydrofractures [27,32-36]. The geometry of the stimulated fractures is typically modeled as a set of rectangular planes, because the focus so far has been the impact of petrological parameters. The impact of the geometry of the effective propped volume, however, remains largely unexplored. In this article, we have developed a 3D numerical model of a standard design of a shale gas well in which, at gas storage level, both the adsorbed gas (Langmuir isotherm) [37,38] and the free pore gas are considered. Inertial effects and slippage are some of the physical effects not considered, although a better approximation of the geometry of the fractured volume (EPV) is sought using a three-dimensional model.

Here we find that the geometry of the fractured zone around the well (EPV) is a key contributor to the performance of a shale gas wells. Traditionally, studies aimed at analyze how to improve production efficiency or economic performance in shale gas wells consider totally flat hydraulic fractures geometry and focus on formation petrology and the induced permeability [26-29]. The importance of this novel discovery is that it allows to lay the scientific bases for new technological developments that improve the efficiency of shale gas wells both in the hydraulic fracturing phase and in a foreseeable later refracturing. Methodologically, we also introduce a 3D numerical modeling shale gas wells. Scientific studies that appear in the literature usually use 1D or 2D models [26-31], but for the purpose of this work we need a 3D model that captures all the flow components around the fractured volumes. The EPVs are modeled as ellipsoidal volumes of high permeability connected to the SRV of lower permeability. The two volumes are fully coupled allowing a higher-fidelity representation of the gas flow in the fractured shale formation which allow us to study the effect of the geometry of the fractured volume on gas production.

To characterize the relative impact of the geometry of EPVs on gas production and economic performance, we carry out a sensitivity study of gas production to other variables such as permeability induced in the SRV, the kerogen content and porosity. By comparing the impact of the variation of these parameters with the variation of the geometry of the fractured zone, we conclude that the geometry plays a fundamental role in gas production. The spherical or flatness of the EPVs is directly related to the surface of the fractured ellipsoidal volumes and to the production time in intermediate power-law-type production regime until the interference between fractures occurs. In general, with the same hydrofracturing volume, flatter fractures, results in higher well productivity. In addition, fractures that are perpendicular to the direction of the well will delay the interference, allowing to maintain the intermediate power-law-type production regime longer [39]. The elucidation of this phenomenon and its impact on economic performance is a novel contribution of this study, which can provide interesting clues to increasing the economic performance of shale gas wells. 


\section{Nomenclature}

Table 1 summarizes the abbreviations used throughout the article, indicating their meaning and physical units.

Table 1. Abbreviations, meaning and units.

\begin{tabular}{ccc}
\hline Abbreviation & Meaning & Units \\
\hline EPV & Effective Propped Volume & $\mathrm{m}^{3}$ \\
SRV & Stimulated Recovery Volume & $\mathrm{m}^{3}$ \\
Mscf & Thousand of standard cubic feet & - \\
MMscf & Million of standard cubic feet & - \\
Bscf & Billion standard cubic feet & - \\
EUR & Estimated Ultimate Recovery & Mscf (Thousand of standard cubic feet) \\
O\&G & Oil and Gas & - \\
BCa & Base Case & - \\
GIP & Gas in Place & Mscf (Thousand of standard cubic feet) \\
RF & Recovery Factor & Dimensionless \\
IRF & Investment Recovery Factor & - \\
MMBTU & Million of British Thermal Units & Dimensionless \\
ROI & Return on Investment & USD (\$) \\
CAPEX & Capital Expenditure & USD (\$) \\
OPEX & Operational Expenditures & Initial Production \\
IP & AR & Mscf/mo (Thousand of standard cubic feet per month) \\
Aspect Ratio & Dimensionless \\
Sn & Dimensionless Ellipsoidal Surface & Dimensionless \\
RFn & Dimensionless
\end{tabular}

\section{Materials and Methods}

\subsection{Mathematical Model}

The mathematical model used in this article takes the form [26,28] (see Table 2 for the definition of all variables):

$$
\begin{gathered}
\alpha \frac{\partial \mathrm{P}}{\partial \mathrm{t}}+\left[\nabla \cdot \frac{\mathrm{c}_{\mathrm{gk}}}{\mu} \mathrm{P}(\nabla \mathrm{P})\right]=0, \\
\alpha=\left(c_{\mathrm{g}} \phi+\rho_{0} \rho_{\mathrm{k}} \mathrm{S}_{\mathrm{k}} c_{\mathrm{f}}\right), \\
\mathrm{P}(\mathbf{x}, 0)=\mathrm{P}_{\mathrm{r}} \text { in } \Omega, \quad \mathrm{P}(\mathbf{x}, \mathrm{t})=\mathrm{P}_{\text {bhp }} \text { in } \Gamma, \\
\mathrm{V}_{\mathrm{a}}=\frac{\mathrm{V}_{\mathrm{L}} \mathrm{P}}{\mathrm{P}_{\mathrm{L}}+\mathrm{P}} .
\end{gathered}
$$

Klinkenberg and Forchheimer effects are not considered in the mathematical model. Regarding the characteristics of the fluid, it is considered a single-phase flow and a single component, and in this case methane $\mathrm{CH}_{4}$ or dry gas.

Table 2 shows the values used in the base model (all in SI units except gas volume, expressed in thousands of standard cubic feet (Mscf); the conversion factor is $1 \mathrm{~m}^{3} \approx 0.0353 \mathrm{Mscf}$ ). 
Table 2. Variables and parameters.

\begin{tabular}{|c|c|c|}
\hline Variable & Meaning & Value \\
\hline SRV & Stimulated Reservoir Vol. & $1.800 \mathrm{~m} \times 600 \mathrm{~m} \times 90 \mathrm{~m}$ \\
\hline EPV & Effective Propped Volume & $300 \mathrm{~m} \times 40 \mathrm{~m} \times 70 \mathrm{~m}$ \\
\hline well length & - & $1.500 \mathrm{~m}$ \\
\hline $\mathrm{P}(\mathrm{x}, \mathrm{t})$ & pressure gas & $(30-5 \mathrm{MPa})$ \\
\hline $\mathrm{P}_{\mathrm{r}}$ & initial reservoir pressure & $30 \mathrm{MPa}$ \\
\hline$P_{\text {bhp }}$ & bottom hole pressure & $5 \mathrm{MPa}$ \\
\hline$c_{g}$ & gas compressibility & $3.979 \times 10^{-6}\left(\mathrm{~s}^{2} / \mathrm{m}^{2}\right)$ \\
\hline$c_{f}$ & Langmuir isotherm slope & - \\
\hline$\phi$ & porosity & $3 \%$ \\
\hline$\rho_{0}$ & $\begin{array}{l}\text { methane density at normal } \\
\text { conditions }\end{array}$ & $0.717\left(\mathrm{~kg} / \mathrm{m}^{3}\right)$ \\
\hline$\rho_{\mathrm{k}}$ & kerogen density & $1250\left(\mathrm{~kg} / \mathrm{m}^{3}\right)$ \\
\hline $\mathrm{S}_{\mathrm{k}}$ & kerogen relative volume & $10 \%$ \\
\hline $\mathrm{V}_{\mathrm{a}}$ & Langmuir isotherm & - \\
\hline $\mathrm{V}_{\mathrm{L}}$ & Langmuir volume & $0.00264\left(\mathrm{~m}^{3} / \mathrm{kg}\right)$ \\
\hline $\mathrm{P}_{\mathrm{L}}$ & Langmuir pressure & $3 \mathrm{MPa}$ \\
\hline $\mathrm{k}_{\mathrm{mf}}$ & main fracture permeability & $2 \times 10^{-15}\left(\mathrm{~m}^{2}\right)$ \\
\hline $\mathrm{k}_{\mathrm{SRV}}$ & SRV permeability & $10^{-17}\left(\mathrm{~m}^{2}\right)$ \\
\hline$\mu$ & methane viscosity & $10^{-4}(\mathrm{~Pa} \times \mathrm{s})$ \\
\hline $\mathrm{M}$ & molar gas of methane & $16.042 \times 10^{-3}[\mathrm{~kg} / \mathrm{mol}]$ \\
\hline $\mathrm{Z}$ & compresibility factor & 1.3 \\
\hline $\mathrm{R}$ & universal gas constant & $8.314462\left(\mathrm{~m}^{3} \times \mathrm{Pa} /(\mathrm{K} \times \mathrm{mol})\right)$ \\
\hline $\mathrm{T}$ & absolute temperature & $373 \mathrm{~K}$ \\
\hline q & methane flux & Mscf/month $\left(1 \mathrm{~m}^{3} \approx 0.0353 \mathrm{Mscf}\right)$ \\
\hline$t_{f}$ & total simulation time & 10 year $\left(3.1536 \times 10^{8} \mathrm{~s}\right)$ \\
\hline$t_{0}$ & initial time simulation & $0 \mathrm{~s}$ \\
\hline$\Omega$ & volume of the SRV & - \\
\hline$\overline{\mathbf{n}}$ & normal vector to contour $\Gamma$ & - \\
\hline n.c. & normal conditions & - \\
\hline
\end{tabular}

Equation (1) is the conservation equation that governs gas flow in the entire computational domain. Coefficients $\alpha$ and $\beta$ are defined in the Equation (2). These coefficients are obtained from the petrological parameters of the hydrofractured formation and the PVT properties of methane. The physical meaning of each of these parameters and the numerical values that we assign are given in Table 2. The compressibility factor of the gas is achieved taking into account the ideal gas equation and isothermal environment.

Equation (3) defines the initial and boundary conditions of the mathematical formulation. An initial condition of constant pressure is established throughout the domain, $\Omega$, that corresponds to the SRV. A Dirichlet-type boundary condition of pressure is imposed on the contours of the well, $\Gamma$, where the gas flow out of the formation occurs.

Finally, Langmuir's isotherm has been included in the mathematical model in order to more accurately represent the adsorption phenomenon Equation (4). In this equation the Langmuir pressure and the Lagmuir volume take values that appear in the Table 2 and that have been obtained from [40].

The methane flow rate is calculated from the evolution of the field pressures as an integral over the well's area $\Gamma$ :

$$
\mathrm{q}(\mathrm{t})=\iint_{\Gamma}\left(\frac{-2 \mathrm{c}_{\mathrm{g}} \mathrm{k}}{\mu} \mathrm{P}\right) \nabla \mathrm{P} \cdot \overline{\mathbf{n}} \mathrm{d} \Gamma .
$$

The cumulative production over the lifetime of the well can be calculated as a time integral of the flow rate $\mathrm{q}_{(\mathrm{t})}$ :

$$
Q(t)=\int_{t_{0}}^{t} q(t) d t, \quad E U R=\int_{t_{0}}^{t_{f}} q(t) d t .
$$


As seen in Equation (6), the estimated ultimate recovery or EUR can be calculated as the value of the final gas production at the end of the study period.

\subsection{Physical Model}

The analysis in this article is based on a standard Base Case (BCa) physical model, schematically shown in Figure 1. In this $\mathrm{BCa}$, we assume ellipsoidal hydrofractured volumes or Effective Propped Volumes (EPVs).

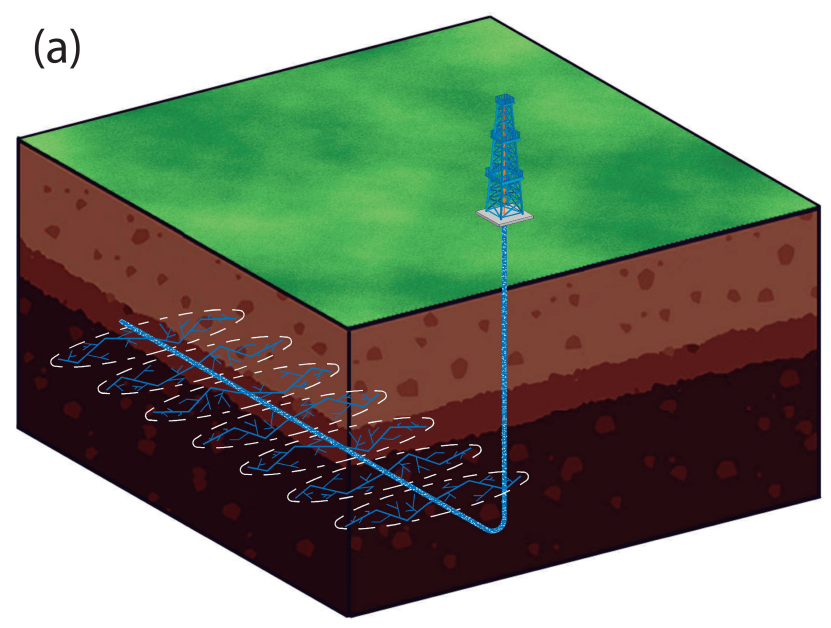

(b)

Figure 1. Physical model. (a) Schematic depiction of the well. (b) Flow in the ellipsoidal EPV.

The BCa is configured by a rectangular prism of $1800 \mathrm{~m} \times 600 \mathrm{~m} \times 90 \mathrm{~m}(\mathrm{SRV})$, located at $3000 \mathrm{~m}$ depth in a shale formation at $30 \mathrm{MPa}$ of pressure and a constant thickness of $90 \mathrm{~m}$. The boundaries of the SRV are considered no-flow boundaries.

Inside the SRV is the well, which is considered horizontally perforated. The length of the well is $1500 \mathrm{~m}$, and seven ellipsoidal hydrofractures are placed every $200 \mathrm{~m}$ (Figure 1a). The wellbore is assumed to be a no-flow boundary except in perforated areas that connect the well with the hydrofractured volumes. In these holes are imposed a physical condition of pressure constant or bottom hole pressure, which is mathematically considered a Dirichlet-type condition Equation (3). The bottom-hole pressure in this BCa is $5 \mathrm{MPa}$.

Each of the hydrofractures or EPVs has an ellipsoidal shape with the following dimensions: $300 \mathrm{~m}$ long in the direction perpendicular to the well and contained in the same plane as this, $40 \mathrm{~m}$ long in the longitudinal direction of the well and $70 \mathrm{~m}$ in the direction perpendicular to the horizontal plane of the formation. Methane gas flows from the entire SRV to the EPVs, and then to the holes in the well casing (Figure 1b).

The formation has a porosity of $3 \%$ with a kerogen content of $10 \%$. The initial permeability in the shale is considered to be on the order of nanodarcies $\left(10^{-21} \mathrm{~m}^{2}\right)$. After the hydrofracturing process, the permeability of the entire SRV increases to $0.01 \mathrm{md}\left(10^{-17} \mathrm{~m}^{2}\right)$ and the permeability of the EPVs reaches $2 \mathrm{md}\left(2 \times 10^{-15} \mathrm{~m}^{2}\right)$.

The adsorbed methane content or Lagnmuir's volume is $0.00264 \mathrm{~m}^{3} / \mathrm{kg}$ of kerogen, and the Langmuir pressure is $3 \mathrm{MPa}$.

We do not consider second-order effects such as the Klinkenberg gas slippage effect or inertial corrections (Darcy-Forchheimer). The development of this model focuses on the geometry of the fracture, as an essential aspect in determining both the quantity and rate of gas production in the well.

We consider single-phase, single-component flow of methane $\mathrm{CH}_{4}$ or dry gas.

The life span of the BCa well is considered 10 years.

Figure $2 \mathrm{a}-\mathrm{c}$ represents the physical model described above. 
(a)

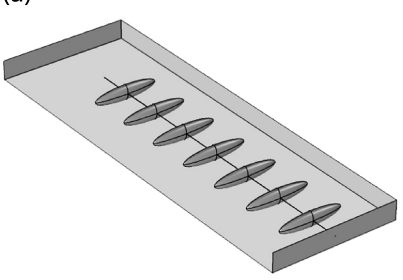

(d)

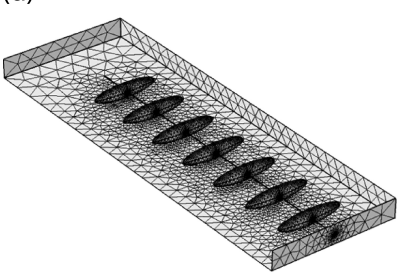

(g)

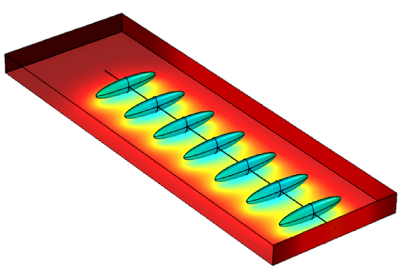

(j)

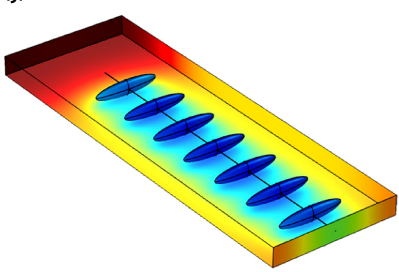

(b)

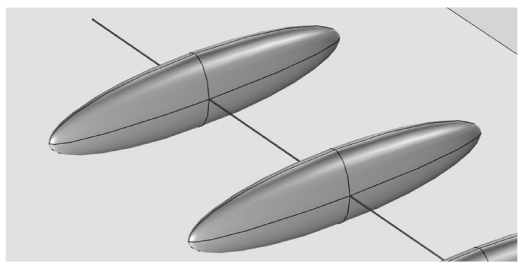

(e)

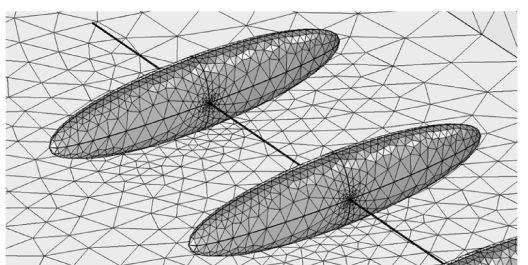

(h)

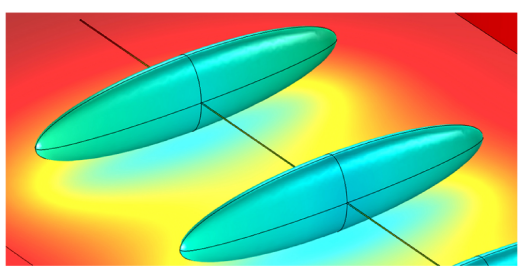

(k)

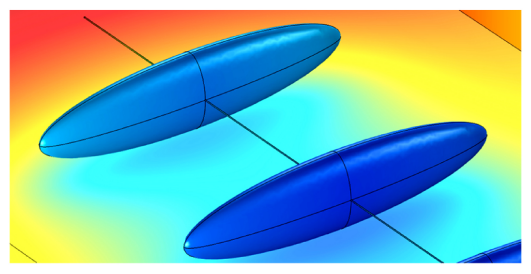

(c)

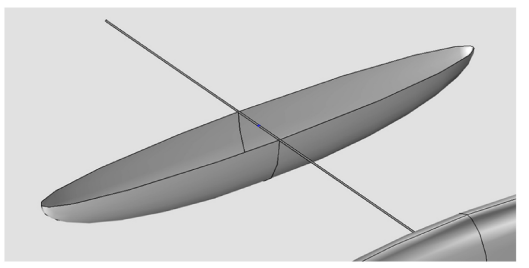

(f)

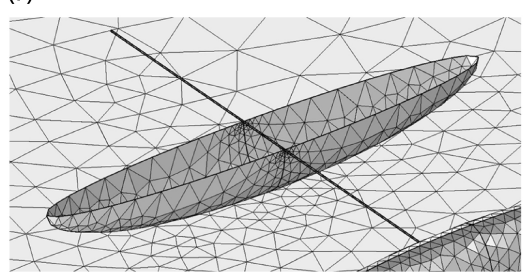

(i)

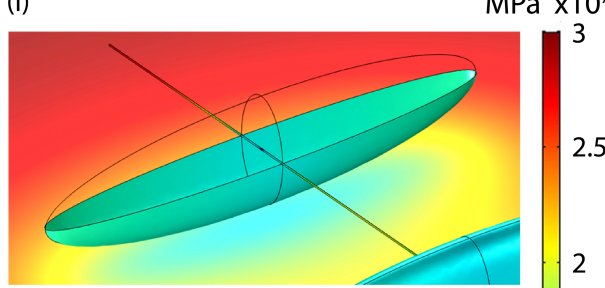

(l)

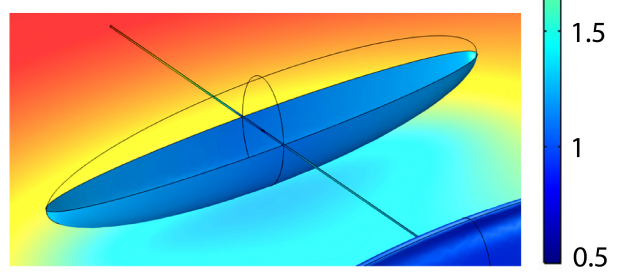

Figure 2. Graphic representation of the physical model, the numerical model and the results of the field pressure. (a-c) Graphical representation of the physical model. (d) Representation of the finite element mesh. (e) Detailed representation of the mesh in ellipsoidal volume fractures or EPVs. (f) Mesh of EPVs. (g-i) State of the field of pressures 3 years after starting the simulation. ( $\mathbf{j}-\mathbf{l})$ State of the field of pressures 10 years after starting the simulation. In this Figure, the upper part of the SRV is not represented, so the pressure state of the main fracturing zones can be seen. In addition, in snapshots $(\mathbf{c}, \mathbf{f}, \mathbf{i}, \mathbf{l})$ the upper volume of the EPVs is also not displayed. This display scheme provides a better view of the evolution of the physical phenomenon of pressure drop that correlates with the gas production over time. Color scale in MPa.

\subsection{Economic Model}

We analyze the economic performance of shale gas wells under various scenarios of petrophysical properties and geometry of the EPVs using well-established metrics.

In addition to defining a physical model of a shale gas well and a mathematical model that allows forecasting gas flow, we define a model of potential gas production and its economic value, as well as the investments necessary to achieve it.

\subsubsection{Gas in Place-GIP}

Gas in Place (GIP) is the amount of gas available in the SRV. We calculate the GIP of the BCa using the Equation (7):

$$
\begin{aligned}
\mathrm{GIP} & =\mathrm{CH} 4_{\text {free }}+\mathrm{CH} 4_{\text {adsorbed }} \\
& =\rho \phi \mathrm{V}_{\mathrm{SRV}}+\rho_{0} \mathrm{~V}_{\mathrm{a}} \rho_{\mathrm{k}} \mathrm{S}_{\mathrm{k}} \mathrm{V}_{\mathrm{SRV}} .
\end{aligned}
$$


Methane density $(\rho)$ and the amount of adsorbed gas varies with pressure and temperature. We include methane state equation and Langmuir isotherm equation in the Equation (7) to transformed into:

$$
\mathrm{GIP}=\left(\mathrm{c}_{\mathrm{g}} \mathrm{P}_{\mathrm{r}} \phi+\rho_{0} \frac{\mathrm{V}_{\mathrm{L}} \mathrm{P}_{\mathrm{r}}}{\mathrm{P}_{\mathrm{L}}+\mathrm{P}_{\mathrm{r}}} \rho_{\mathrm{k}} \mathrm{S}_{\mathrm{k}}\right) \mathrm{V}_{\mathrm{SRV}}
$$

Applying values that appear in Table 2 to Equation (8), the GIP value for the BCa is:

$$
\begin{aligned}
\mathrm{GIP} & =368,990,640 \mathrm{~kg} \text { of } \mathrm{CH}_{4} \\
& \approx 1.82 \cdot 10^{7} \mathrm{Mscf} \mathrm{CH}_{4} \\
& =18.2 \mathrm{Bscf} \text { of } \mathrm{CH}_{4} .
\end{aligned}
$$

Considering a price of $2.61 \$ / M M B T U \equiv 2.71 \$ /$ Mscf (source: EIA; Henry Hub Natural Gas Spot Price, 17 May 2019), then the GIP in this BCa has a market value of $\approx \$ 46 \mathrm{MM}$.

\subsubsection{Capital Expenditure-CAPEX}

Capital Expenditure or CAPEX is the investment that is necessary to carry out the execution of the well. To calculate the CAPEX value we use the Equation (10).

$$
\mathrm{CAPEX}_{\mathrm{BCa}}=\mathrm{C}_{\text {lease }}+\mathrm{C}_{\text {drill }}+\mathrm{C}_{\text {frac }} .
$$

Using the financial data appearing in $[40,41]$, we evaluate the BCa CAPEX:

$$
\begin{aligned}
\text { CAPEX }_{\mathrm{BCa}} & =1800 \mathrm{~m} \cdot 600 \mathrm{~m} \cdot 0.25 \frac{\$}{\mathrm{~m}^{2}} \\
& +1500 \mathrm{~m} \cdot 1250 \frac{\$}{\mathrm{~m}} \\
& +7 \text { stage } \cdot 375,000 \frac{\$}{\text { stage }} \\
& =\$ 4.8 \mathrm{MM} .
\end{aligned}
$$

We present Equation (10) in a generic formulation that allows its application to any shale gas well in any oil field.

Equation (11) expresses the execution cost of BCa shale gas well defined in Figure 1a.

\subsubsection{Recovery Factor-RF}

It is the most common parameter to evaluate the degree of efficiency in hydrocarbon well production. It is calculated using the Equation (12).

$$
\mathrm{RF}=\frac{\mathrm{EUR}}{\mathrm{GIP}}
$$

The Recovery Factor (RF) is a metric that allows to determine the effectiveness in gas extraction process. It measures as a percentage how much gas is extracted at the end of the useful life of the shale gas well (EUR) of the total gas available in the formation (GIP) [42-44]. Typical RF values in shale gas production range from $10-20 \%[42,45,46]$.

\subsubsection{Investment Recovery Factor-IRF}

We create an index that relates the amount of gas produced, in economic terms, with its CAPEX. This index can be defined as an Investment Recovery Factor (IRF), which is the relationship between the EUR and CAPEX expressed in financial terms. Mathematically the IRF could be expressed as follows in Equation (13). Therefore, if the parameters used give an IRF of less than 1, then it is clear that the economic performance of the well for these parameters is not profitable, at least at the time of study. In contrast, if it is greater than 1 
we can assume that, at least, the initial CAPEX will be recovered, assuming the hypothesis of a constant gas price over the life span of the well:

$$
\mathrm{IRF}=\frac{\mathrm{EUR} \cdot \text { Price gas }}{\mathrm{CAPEX}}=\frac{\mathrm{RF} \cdot \mathrm{GIP} \cdot \text { Price gas }}{\mathrm{CAPEX}} .
$$

The IRF gives us a quick metric for the economic sensitivity analyses carried out in this study.

\subsection{Numerical Model}

We implement the mathematical Equations (1)-(4) in a 3D model using the finite element software COMSOL Multiphysics ${ }^{\circledR} 5.4$ [47]. We develop the numerical model as follows:

- We define SRV geometry according to the dimensions that appear in the Table 2.

- We consider SRV outer contour numerically a no-flow boundary condition.

- We model the horizontal well as a horizontal cylinder. We erase this cylinder volume from the SRV generating an inner no-flow boundary condition. Physically, this no-flow contour corresponds to the placement of a metal casing.

- We generate seven sections in the horizontal well in which the contour is permeable and in which pressure Dirichlet-type condition is imposed $\left(\mathrm{P}_{\mathrm{bhp}}\right)$. These seven sections correspond to the points where the projectile launcher pierces the well casing.

- We create seven ellipsoidal volumes (EPVs) of high permeability according to the dimensions that appear in Table 2.

- We mesh the whole BCa with 155,561 tetrahedral element. The quality of the elements ranges from 0.08 to 0.63 on a dimensionless scale with the range $0-1$.

- Mesh closest to the well and EPVs is finer to be able to capture well the phenomena of strong methane flow that occurs near to the wellbore at early times. Mesh furthest from the well and the EPVs is much more coarse since the pressure gradient in this area is smaller, Figures $2 \mathrm{~d}-\mathrm{f}$ and $3 \mathrm{~g}, \mathrm{~h}$.

- We incorporate the mathematical model defined in Equations (1)-(4) with the parameters of Table 2.

- The simulation time is 10 years and the time step is 36.5 days.

- Using this model, we calculate the field pressure evolution over time. With this field pressure we compute the flow rate and the cumulative methane production by applying Equations (5) and (6) in the seven production areas.

This workflow is graphically represented in Figure $3 a-h$.

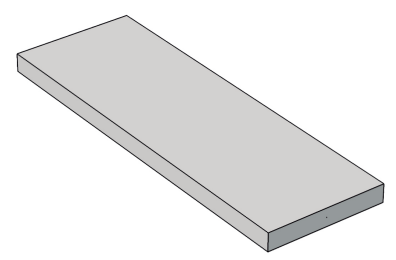

(a) SRV Geometry

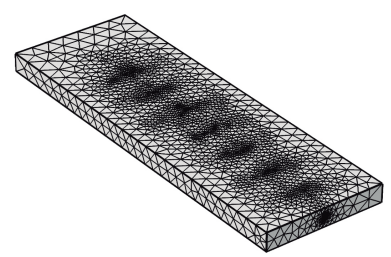

(e) BCa Mesh

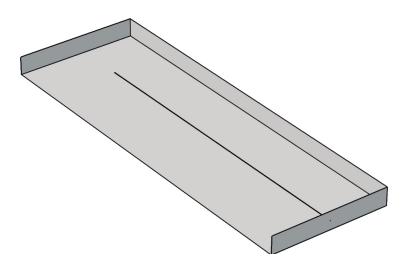

(b) Well Geometry

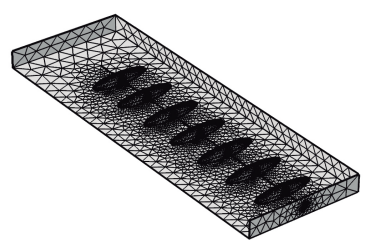

(f) Mesh inside BCa

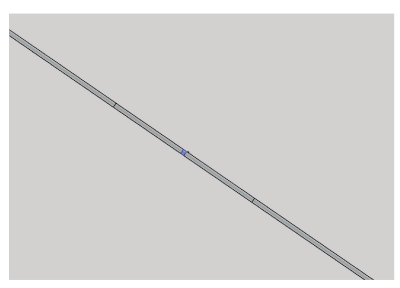

(c) Gas flow zone in "blue"

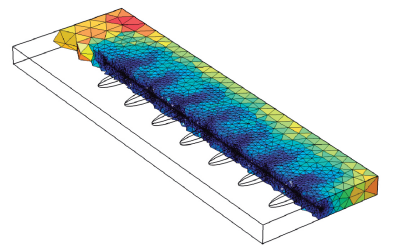
(g) Longitudinal Cross Section Mesh

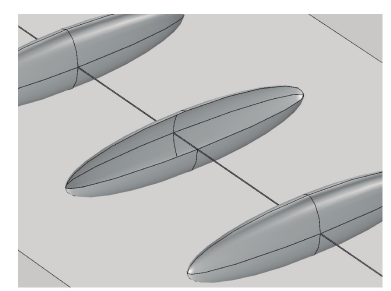

(d) Ellipsoidal EPVs

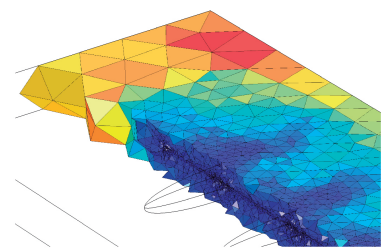

(h) Cross Section Mesh (Detail)

Figure 3. Schematic representation of the workflow of the numerical modeling process, (a-h). 


\subsection{Models Discussion}

The models we use in this study require a discussion and explanation of their limitations:

- The mathematical model is generalist and fully applicable to other shale gas wells. At the technological level, we have included the most relevant phenomena.

- The defined physical model is considered for a specific Base Case with a specific geometry. However, what we seek in this study is to qualitatively characterize the relative importance of the geometry of the EPVs in relation to other parameters (e.g., porosity). For this purpose, the physical model that we have presented is completely valid.

- The economic model is qualitative valid and generalize to other shale gas wells. Its quantitative results are limited by the assumption of the fixed gas price throughout the life of the shale gas well.

- The methodology to develop the 3D numerical model is applicable to any other shale gas well design.

\section{Results and Discussion}

\subsection{Pressure State Analysis}

Pressure field values vary from a maximum pressure of $30 \mathrm{MPa}$ to the pressure imposed as a boundary pressure or bottom hole pressure, $\mathrm{P}_{\text {bhp }}$ of $5 \mathrm{MPa}$ (Figure $\left.2 \mathrm{~g}-1\right)$ ). After 3 years the effect of lowering the pressure has reduced the pressure in the EPVs considerably. The rest of the SRV begins to be affected by this effect and begins to drain the methane in the well (Figure 2g-i). After 10 years the pressure decline affects most of the SRV. Between the EPVs it is observed how the pressure drops of the hydrofractures cross, reaching what is known as "interference"; a process by which the pressure drop in neighboring fractures interacts with each other by changing the gas production regime [28]. Lowering the pressures is sufficient to mobilize most of the free pore gas and a significant fraction of the gas adsorbed in the hydrofracture volumes. Comparing Figure $2 \mathrm{~g}-1 \mathrm{can}$ be seen how the pressure drop has a very rapid effect on the pressure state of EPVs, while the rest of the SRV pressure declines much more slowly. This effect has its origin in the difference of permeabilities between the ellipsoidal fracture volumes and the rest of the SRV. Dirichlettype boundary condition imposed on the holes of the well produces a strong decrease in the pressure field and a strong methane flow. This strong pressure gradient can be seen as a small deep-blue colored area on the cylinder that defines the horizontal well, Figures 2i,l.

\subsection{Methane Production Analysis and Economic Performance}

The gas production regime is depicted in Figure 4a-c. This Figure shows how the flow rate and its regime (Mscf/mo), and the total cumulative production (Mscf) are adjusted, both qualitatively and quantitatively, to the classic unconventional gas well production models that appear in the literature [26-28,48].

Qualitatively, an early-time regime appears in the production rate, followed by a intermediate power-law-type regime and finally, when the fractures enter into interference, an exponential decay regime (Figure 4c). Likewise, the cumulative production gradually increases more slowly each time, following the typical production curve.

From a quantitative point of view, this well would produce as an initial production (IP) gas rate of $80 \mathrm{MMscf} / \mathrm{mo}$, and a total accumulated gas in 10 years of $3 \mathrm{Bscf}$. This implies an RF of $21 \%$. This cumulative gas at a gas price of 2.71 \$/Mscf implies that the total production in financial terms would be $\$ 8 \mathrm{MM}$. The IRF, as defined in Equation (13), takes the value of 1.69 for the $\mathrm{BCa}$. This implies that for the well of the $\mathrm{BCa}, 100 \%$ of the initial financial investment or CAPEX is covered and there is still $69 \%$ with respect to CAPEX to cover the operating expenses or OPEX and obtain profits during the lifetime of the well. This Initial Production (IP) flow rate, the RF and the accumulated production falls within reasonable parameters for a shale gas well [42,49-52]. 

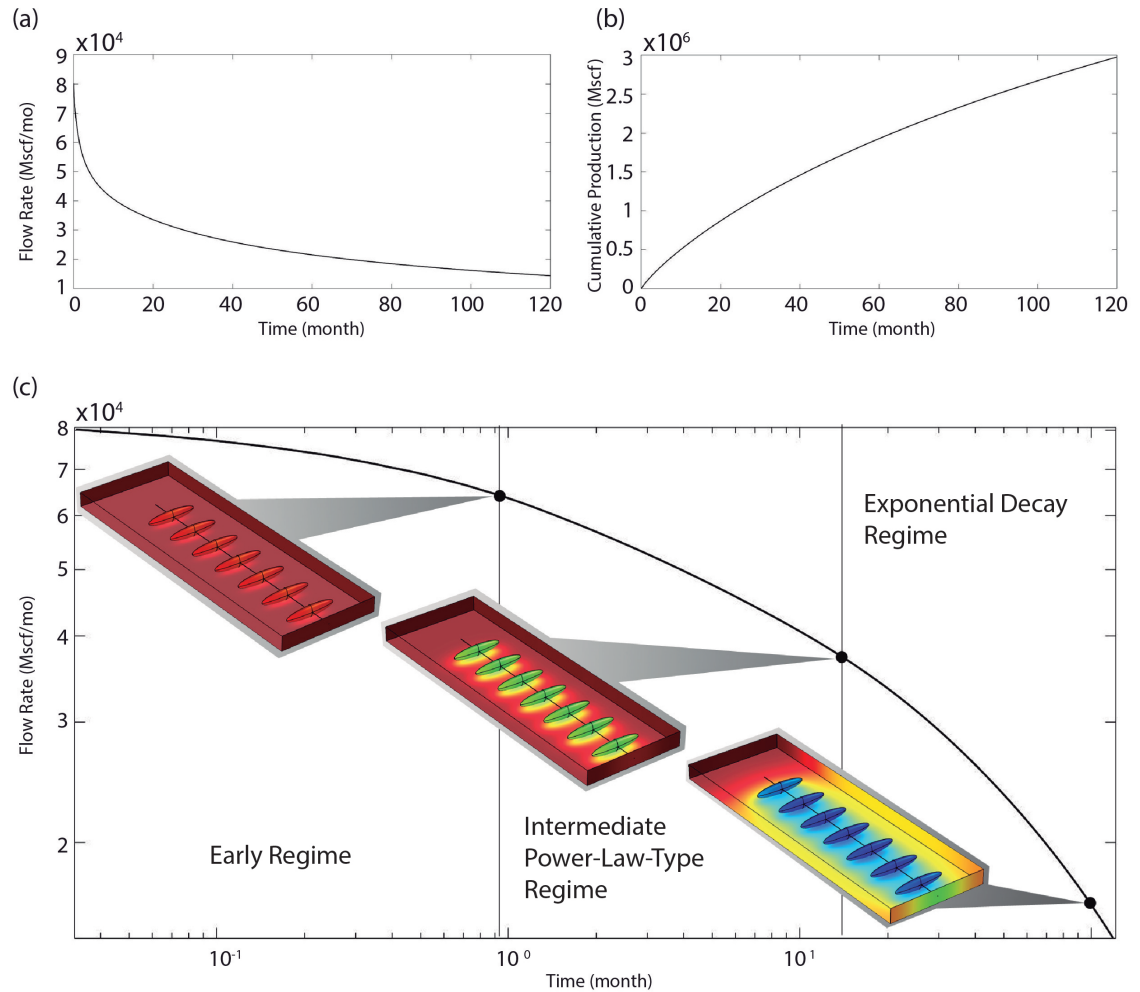

Figure 4. Gas production graph. Flow rate (a) and cumulative production (b) of methane in linear scale. (c) Flow rate of methane in log-log scale. Ten year simulation.

\subsection{Economic Sensitivity Analysis. Comparison of the Variation of Porosity, Permeability and Kerogen}

In this section we analyze the economic sensitivity of the $\mathrm{BCa}$ to the key variables affecting the gas production, and compare them with each other to assess their impact on gas production and economic performance.

While porosity and permeability are often strongly correlated in geologic media, it is not obvious how they may correlate in the case of shale formations stimulated through hydraulic fracturing. We have thus decided to very them independently in this study.

\subsubsection{Porosity}

For the porosity analysis, its value is varied for each simulation between $1 \%$ and $5 \%$, in increments of $0.5 \%$, giving us a total of nine scenarios. This range of porosities has been determined from $[53,54]$. Regarding the RF, an unexpected phenomenon occurs when the porosity changes: as the porosity increases, the RF decreases. In other words, as the increase in GIP is much more relevant than the increase in EUR, the RF decreases, Figure $5 \mathrm{~b}$ (blue dots). However, the IRF increases with porosity, and this can be seen in the same Figure $5 \mathrm{~b}$ (red dots). This is because an increase in porosity increases the EUR, although the CAPEX of the well does not depend on the porosity and the gas price is considered constant.

In order to analyze the behavior of the model for porosity values of less than $1 \%$, we have carried out an additional simulation of $0.5 \%$. This small value is probably outside the range in which shale gas formations are commercially viable, but performing a calculation at low porosity allows us testing the numerical model in cases of extreme values.

The change in porosity has a very important impact on the total gas production and the IRF in the 10 year exploitation period. That is, for a porosity of $1 \%$ at 10 years of production, the money obtained does not cover the well's initial investment, CAPEX. However, at 5\% porosity the economic production increases two fold. Enough to cover CAPEX and obtain extra profits. 
We can also see how as porosity increases, RF decreases. However, the IRF increases. We explain this since although the EUR and the GIP increase with porosity, the increase of the GIP is proportionally much greater than that of the EUR. We observe how the IRF always increases, since the change in porosity does not alter the CAPEX. This leads us to the conclusion that in some cases we could find an economically profitable but inefficiently exploited shale gas play. As we can see, the results we obtain indicate that the model is robust.

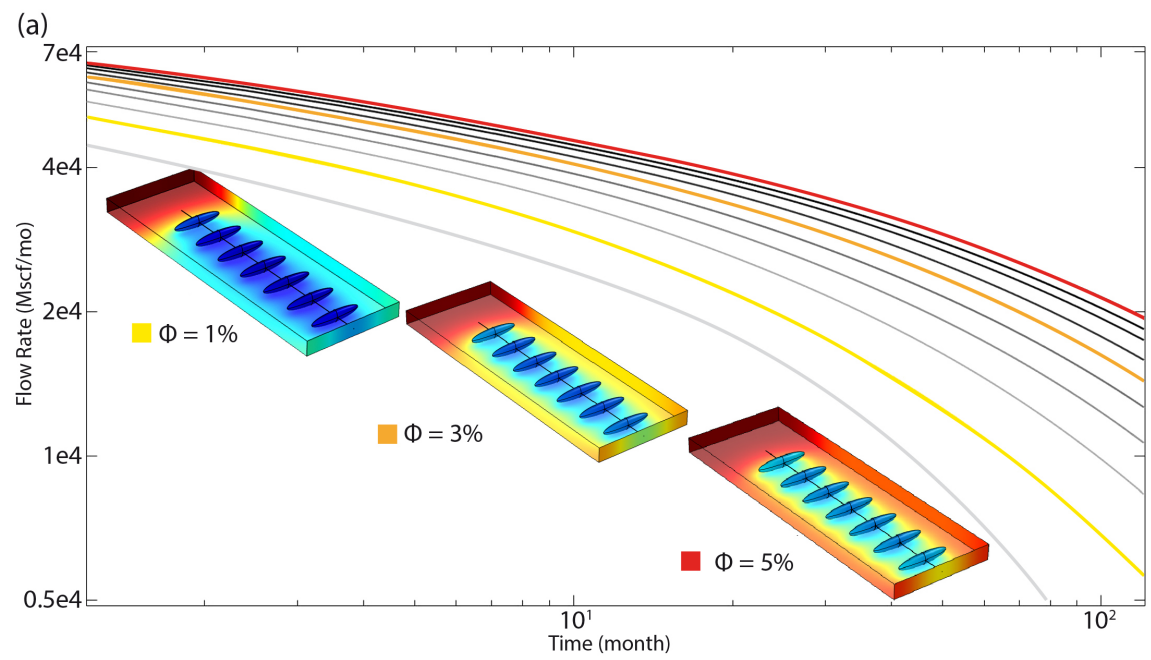

(b)

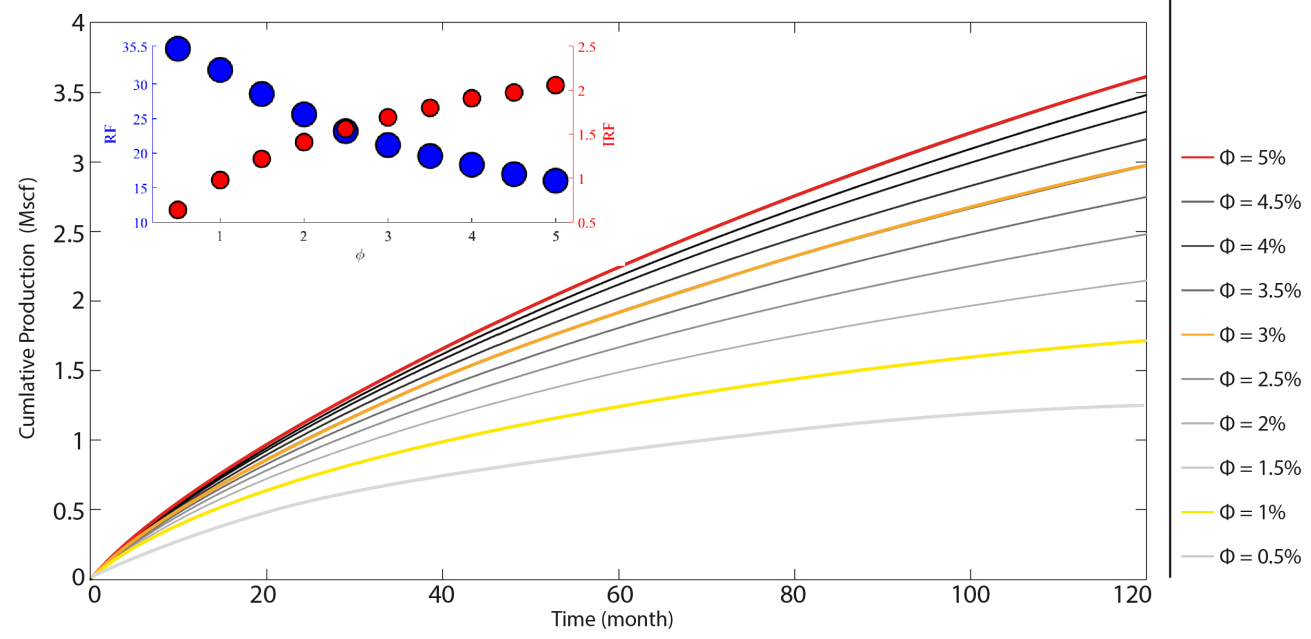

Figure 5. Impact of porosity. Flow rate production of methane in log-log scale. The snapshots represent the BCa field pressure for different porosity values (a). Cumulative production of methane in log-log scale (b). Ten year simulation. Field pressure colormap takes the value range that appears in the Figure 2g-1. In the inset of this Figure, "red dots" (IRF) have been represented smaller than "blue dots" (RF) to avoid graphic intersections between both data.

Regarding the flow rate and cumulative production regimes for the different porosity values, it is observed that the lower the porosity, flow rate and cumulative production curves decrease in value at all step times of the 10-year simulation, Figure 5.

\subsubsection{Permeability}

In this analysis, we vary the permeability over one order of magnitude. This variation is made only in the SRV, considering that the EPVs have a permeability that remains constant. The parametric sweep of the permeability ranges from $1 \mu \mathrm{d}\left(10^{-18} \mathrm{~m}^{2}\right)$ to $10 \mu \mathrm{d}$ $\left(10^{-17} \mathrm{~m}^{2}\right)$ in intervals of $0.9 \mu \mathrm{d}$ which implies the evaluation of 11 scenarios. 
The influence of permeability on production is very strong, see Figure $6 \mathrm{~b}$. A change of an order of magnitude in the permeability of the SRV causes a two-fold increase in production. It should be noted that the change in permeability does not affect the GIP. For this reason, when the IRF analysis is performed, it can be seen that as the permeability increases, the IRF increases with a ratio similar to that of the RF. This suggests that induced permeability is a determining factor in the exploitation efficiency of the GIP in the formation and adequate performance of the investment in the well.

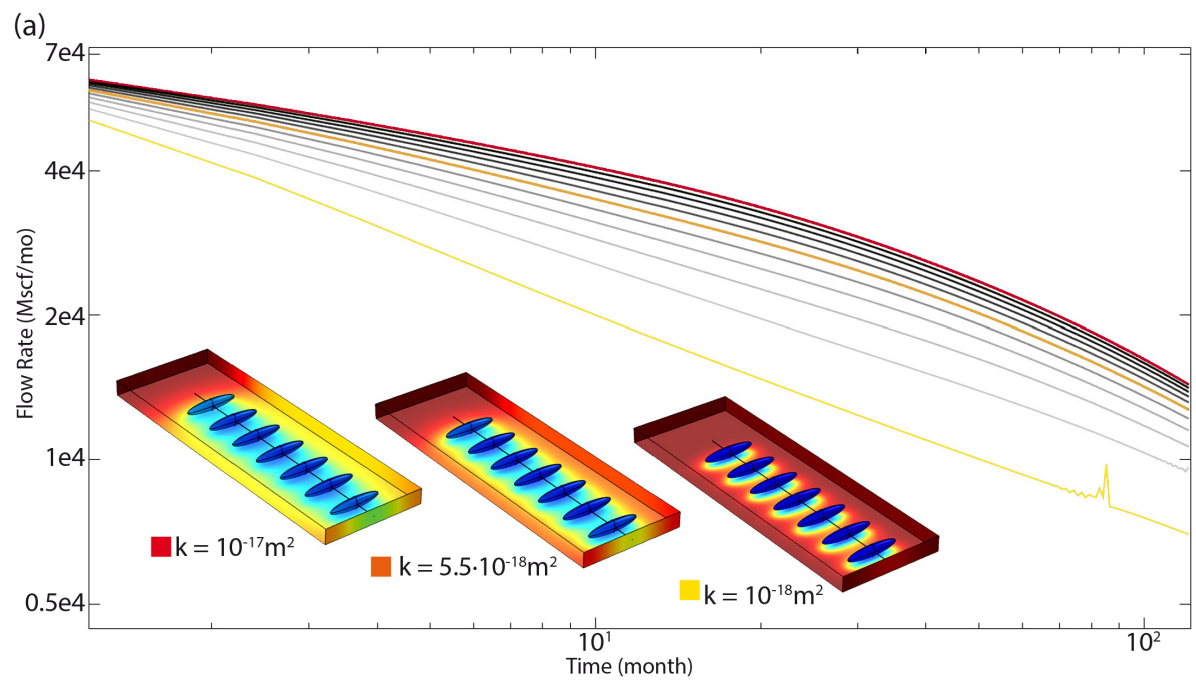

(b)

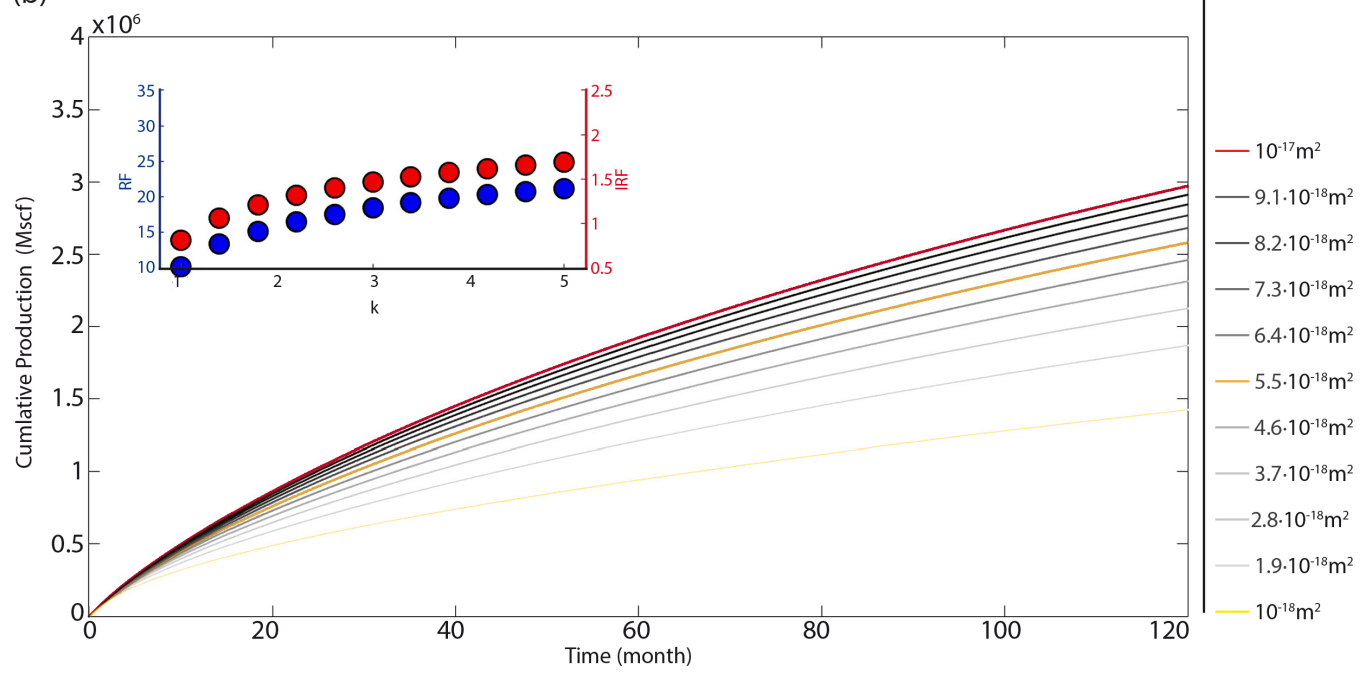

Figure 6. Impact of permeability. Flow rate production of methane in log-log scale. The snapshots represent the BCa field pressure for different permeability values in the SRV (a). Cumulative production of methane in log-log scale $(\mathbf{b})$. Ten year simulation. Field pressure colormap takes the value range that appears in the Figure $2 \mathrm{~g}-1$.

In relation to flow rate regime, it can be observed how the production curve becomes straighter as the permeability decreases. This indicates that the production regime of the curve does not enter exponential decay and remains in the power-law-type production regime, Figure 6a. The snapshots of this Figure 6a show how, at low permeability, the pressure field at the end of the simulation (10 years) only affects the ellipsoidal volumes. As the permeability increases, it can be clearly seen how the whole of the SRV is affected by the pressure drop and not only the EPVs. This is reflected in the flow rate production curves in which the most marked exponential decay is observed as the permeability increases. Regarding the cumulative production, the regime of the curves is not altered, but the accumulated production is lower as the permeability decreases. 


\subsubsection{Kerogen Content}

The kerogen is a part of the total organic matter present in the source rock of the hydrocarbon and defined as the part of the organic matter insoluble to organic compounds [55]. It is generally considered to be the material to which the gas of a formation is adsorbed. There are different models to explain the kerogen gas adsorption process but the most studied and accepted in unconventional formations engineering is the Langmuir model [56].

Here we vary, the amount of kerogen between $1 \%$ and $15 \%$, performing simulations every 2 percentage points, so eight scenarios are carried out. As in the case of the porosity, the changes in the kerogen directly affect the amount of the GIP. Therefore, a similar situation to that with the porosity will occur as the kerogen increases. As the amount of kerogen increases, the RF decreases. There is more gas available in the SRV with the increase in kerogen, adsorbed gas, although proportionally the gas extracted becomes less and less compared to the available amount, GIP (see snapshot Figure 7b). The IRF increases as the kerogen and the available gas increases. The explanation for this phenomenon is identical to that given in the case of the porosity. It can be seen how the amount of kerogen does not affect the CAPEX. In any case, as can be seen in Figure $7 \mathrm{~b}$ the sensitivity of both the RF and IRF to the amount of kerogen is very low.

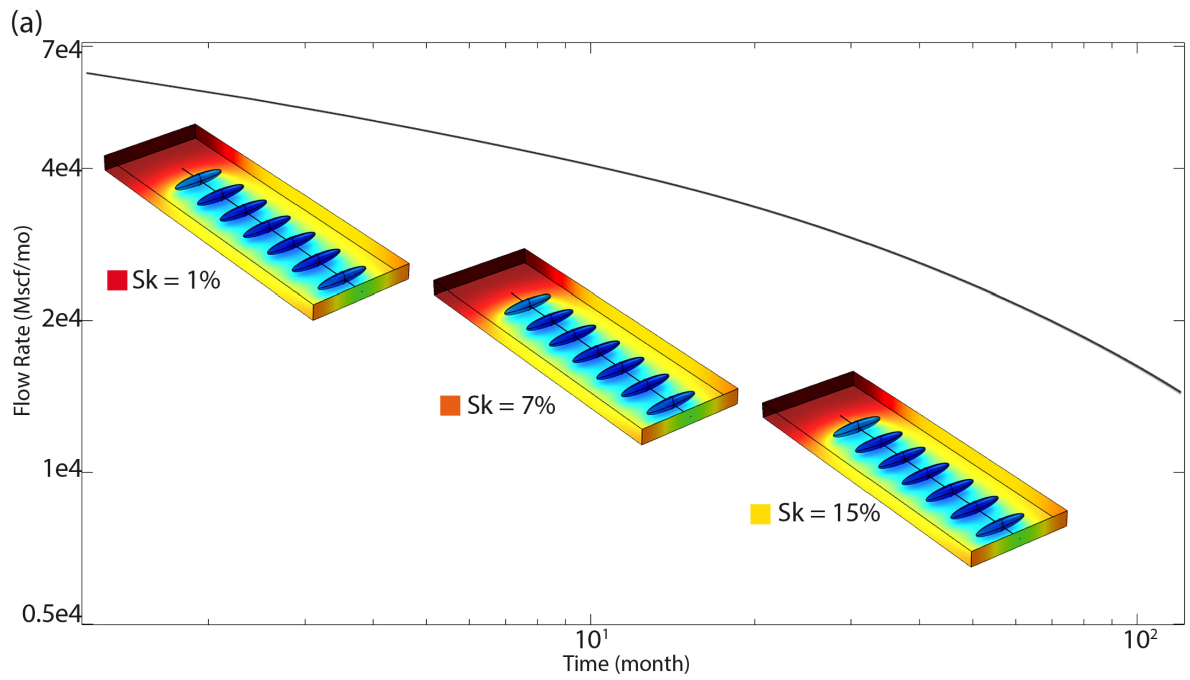

(b)

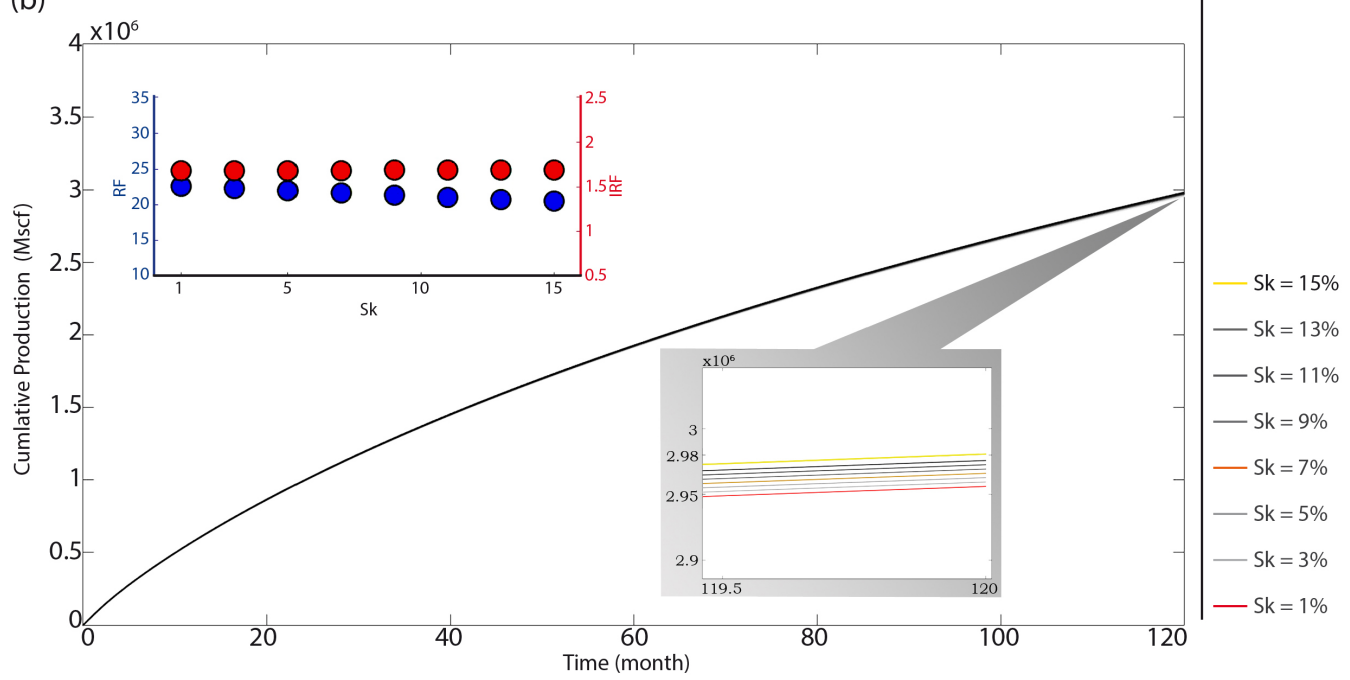

Figure 7. Impact of kerogen content. Flow rate production of methane in log-log scale. The snapshots represent the BCa field pressure at the end of the well life for different kerogen content (a). Cumulative production of methane in log-log scale (b). Ten year simulation. Field pressure colormap takes the value range that appears in the Figure $2 \mathrm{~g}-1$. 
Neither the flow rate nor cumulative methane production regimes are significantly affected by the variation in the amount of kerogen. Very minor differences can be observed in the zoomed view in Figure $7 \mathrm{~b}$. According to the study carried out, the amount of kerogen does not decisively influence the production results or the economic performance for the BCa, as can be seen in Figure 7.

\subsection{Impact of the Variation of Fracture Geometry on the Economic Performance of Shale Gas Wells}

In this section, we will analyze how the EPVs geometry can decisively influence the economic performance of the shale gas wells, comparing this aspect with the three parameters previously analyzed: porosity, induced permeability in SRV and amount of kerogen.

When hydrofracturing fluid is pumped, a local fracture occurs in the shale area around the well. The hydrofracturing phase is one of the most expensive in the deployment and implementation of a shale gas well. The cost of the each hydrofracturing phase correlates with the volume of fracturing fluid, which in turn correlates with the volume of fractured shale (EPVs). For a given volume of fluid, the geometry of the hydrofracture can change, becoming flatter or more spherical. The orientation can also vary from being perpendicular to the direction of the well to following the direction of the well. The EPV is considered an ellipsoidal volume, a geometric characteristic indicated in [15,17-25]. Other geometries are not considered. Quasi-spherical geometries will be taken into account as particular cases of the geometric variations of the EPVs. The well is considered to be completely horizontal and contained in the shale-like play. With these considerations, the axis aligned with the well is denoted by the letter $b$. The axis perpendicular to the well and contained in the horizontal play is named $a$. Both axes, $a$ and $b$, are variable in length. Finally, the axis perpendicular to the play is named $c$ and its length is considered constant. We also assume that the volume of the ellipsoids remains constant, which in turn is directly related to the volume of the hydrofracturing fluid and its cost. Keeping the length of $c$ and the volume of the ellipsoids constants implies that when we vary the shape of the EPVs, the lengths $a$ and $b$ axes will be related in such a way that when $b$ increases, $a$ will decrease and vice versa. The volume of each EPV is:

$$
V=\frac{4 \pi}{3} \cdot a \cdot b \cdot c=\frac{4}{3} \pi \cdot 150 \cdot 20 \cdot 35=4.4 \cdot 10^{5} \mathrm{~m}^{3} .
$$

We use the Aspect Ratio (AR) $b / a$ to represent the level of fracture flatness and the orientation of said fracture in the vertical plane. When the AR is low (e.g., 0.01), the fracture is flat and perpendicular to the well, and when the AR value is high (e.g., 7), the fracture is flat but aligned with the well. We adopt the Aspect Ratio $b / a$ both axes are variable, keeping the volume of the EPVs constant. Other Aspect Ratios such as $b / c$ or $a / c$ will not be considered since $c$ is an axis of constant length, it does not allow to consider the joint variability of $a$ and $b$ in a single parameter, which gives us information about the flatness and the direction of said flatness; perpendicular or longitudinal to the well. In addition, the consideration of other Aspect Ratios would make sense if they were essentially horizontal, but this fact does not generally occur since the most important normal principal stress is vertical.

We change geometry of the EPVs keeping the cost of hydrofracturing the same. The AR is varied from 0.05 which represents a very flat geometry, perpendicular to the well and with an ellipsoidal semi-axis $a$ of $235 \mathrm{~m}$ that almost reaches the limits of the SRV up to an $\mathrm{AR}$ value of 7.5 that corresponds to a flat fracture, longitudinal to the well, with an $a$ of $20 \mathrm{~m}$ that makes the value of the semi-axis $b$ reach $150 \mathrm{~m}$ and touches the edge of the SRV, generating an intersection of the EVPs. We conduct a total of 17 simulations between these two AR values. In the snapshots of Figure 8a, we show the different geometries of the fracture ellipsoids can be observed and the field pressure after 10 years of simulation. Note how the shape of the EPVs changes considerably and with it the pressure field. $A R$ variations do not affect the GIP, but they do affect the physical process of gas extraction 
as we will show, modifying the EUR, and therefore as the RF increases the IRF increases and as the RF decreases the IRF decreases.

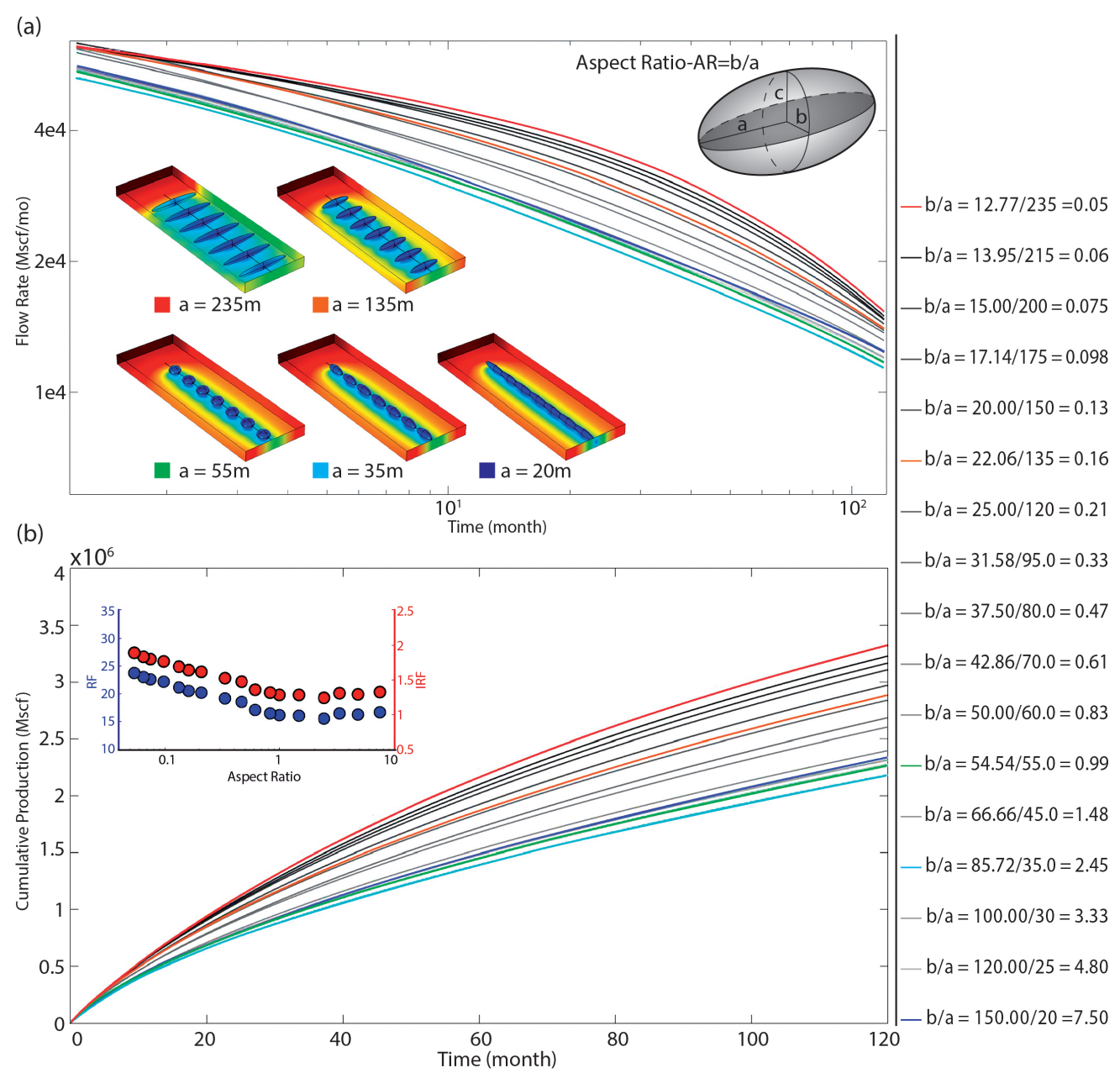

Figure 8. Impact of EPV geometry. Flow rate production of methane in log-log scale. The snapshots represent the BCa field pressure at the end of the well life for different lengths of the $a$ axis. Each of them corresponds to an AR value (a). Cumulative production of methane in log-log scale. (b) Ten year simulation. Pressure field colormap takes the value range that appears in the Figure $2 \mathrm{~g}-1$.

Following the simulations, it is observed how there is a minimum $\mathrm{RF}=15.6 \%$ for an $\mathrm{AR}=2.45$ and in the extreme values of $\mathrm{AR}$ the value of $\mathrm{RF}$ is higher. An identical situation occurs for the IRF, with a minimum in $A R=2.45(\mathrm{a}=35 \mathrm{~m})$ of $\mathrm{IRF}=1.24$. Absolutely quantifying the economic amount of the IRF variation between $A R=2.45(\mathrm{a}=35 \mathrm{~m})$ and $\mathrm{AR}=0.05(\mathrm{a}=235 \mathrm{~m})$ results in $\$ 2.9 \mathrm{MM}$, a very significant quantity compared to the CAPEX, \$ 4.8 MM.

In relation to the flow rate production regime, it is observed how changes in the AR, considerably affect this regime. As the AR increases, the curve becomes more "flat" or "straight". This trend is similar to that found when analyzing the flow rate as a function of permeability.

In the snapshots that appear in Figure 8a it can be seen how in perpendicular flat fractures after 10 years of simulation (operation time), practically all the SRV is affected by the pressure drop. However, for longitudinal flat fractures it is observed that as the pressure drop is more local and around the fractured areas, and even in more spherical fractures, a similar situation occurs with little effect on the SRV. In addition to the above, it can be seen how there is a decline production curve and cumulative production curve that generate the lowest values of Mscf/mo and Mscf (respectively) over time and do not correspond to the fracture geometry with higher or lower AR, but have an intermediate value AR = 2.45 
$(\mathrm{a}=35 \mathrm{~m})$, resulting in the curve that generated the lowest RF and the lowest IRF, which makes sense. This is explained in more detail in the following section.

\subsection{Physical Explanation for the Impact of Geometry on the Performance of Shale Gas Wells}

Two physical phenomena explain there is such a significant impact on gas production and on the economic performance of the well as the geometry of EPVs varies:

- The surface of the fractured ellipsoids. At equal fracturing volume, which in turn is proportional to the volume of injected hydrofracturing fluid, the flatter the ellipsoid the greater its area and the closer to sphericity the ellipsoid the smaller its area. The larger the surface of the EPVs, the more methane is extracted from the formation. Equation (15) defines the surface of an ellipsoidal volume with an error estimated at $\epsilon=|1.061| \%$

$$
S \approx 4 \pi\left(\frac{a^{p} b^{p}+a^{p} c^{p}+b^{p} c^{p}}{3}\right)^{\frac{1}{p}}, p \approx 1.6075 .
$$

- Interference between fractures. This phenomenon occurs when the pressure drop induced by the gas leakage towards the well in each fracture, generates a change in the field pressure that propagates over the entire SRV. By the time the pressure drops in each fracture begin to overlap with each other, interference is said to have been reached. At this time, there is a change in the gas production regime going from a power-law-type regime to an exponential decline, that is, an accelerated decrease in production.

We use the RF to analyse in more detail how the AR and the associated physical factors described above influence the variation in the well performance. The conclusions we reach for the RF are valid for the IRF, as RF and the IRF correlate with the variation of AR following the same pattern, Section 4.4.

We carry out our study using the data from the 17 simulations that have been executed in the parametric sweep of the AR.

For each of the simulations, the surface area of the ellipsoidal fractured volumes corresponding to each AR is calculated using Equation (15). These values are normalized by dividing each value by the maximum of all of them, obtaining normalized Surfaces, Sn, for each AR. On the other hand, each RF is also dimensionless, obtaining a normalized $\mathrm{RF}, \mathrm{RFn}$, for each value of AR. We represent the pairs (Sn, RFn) graphically and we show how there is a fairly good linear correlation $\left(R^{2}=0.7401\right)$ between both pairs of values. This means that the greater the surface area of the EPV, the greater the RF with a linear trend. We present this phenomenon in Figure 9a. In addition, we show how there are two "branches" within the graph. If the values of lower AR (flatter and perpendicular to the well) are treated separately from those with higher AR (also flatter, but longitudinal to the well), it can be observed how the linear relationship changes significantly.

Lower ARs improve the linear correlation significantly, achieving an adjustment with $a R^{2}=0.9146$. These values are represented in dark red in Figure 9a.

On the other hand, we draw the pairs (Sn, RFn) corresponding to high AR in dark green, Figure 9a. If there is an intersection between fractures, we mark with a square symbol. Values of higher AR lose linear adjustment with a $\mathrm{R}^{2}=0.4063$.

To understand why there are these differences, we analyze the interference between fractures. For this purpose, the isosurface of the pressure gradient of $5 \mathrm{kPa} / \mathrm{m}$ is represented after 365 days of simulation and we check the interference for the different AR values. It is observed that when the EPVs have a low AR geometry, there is no interference between fractures, so the linear correlation between RF and the ellipsoid surface is very clear. However, when the EPVs have a high AR geometry, interferences occur very early. This alters the relationship between RF and ellipsoid surface breaking the linearity of the relationship between RF and ellipsoid surface and further reduces RF considerably. This is because early interference causes the well production to enter in exponential decay so the flow rate reduces rapidly. In addition, if the AR is especially high, then the fractures 
intersect which moreover reduces the fracture surface. Figure $9 b$ shows interferences for different EPV Aspect Ratios. The economic efficiency of a shale gas well in relation to the shape of EPVs, for a given hydrofracturing volume depends on the flatness and orientation of the EPVs. The flatter the EPVs and the more perpendicular to the well, the higher the gas production and the economic performance of the shale gas well. We emphasize this last point since the increase in efficiency based on the management of the geometry of the EPVs will only be achieved assuming the accomplishment of geometric parameters that define a fractured ellipsoidal volume of the characteristics described in this study.

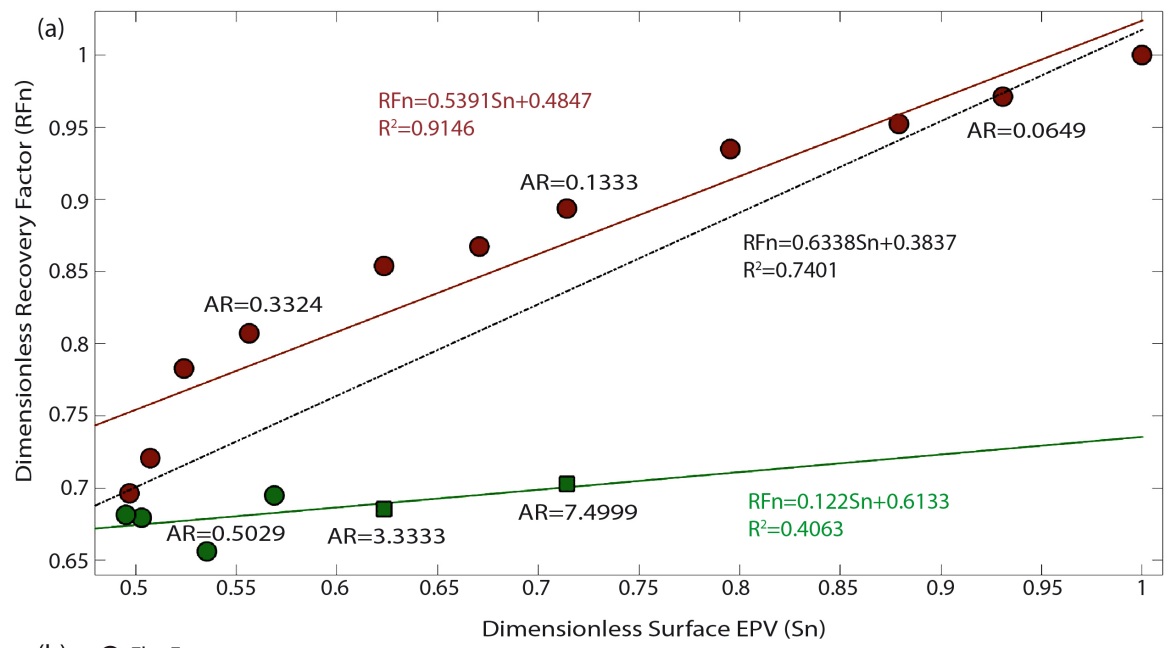

(b)

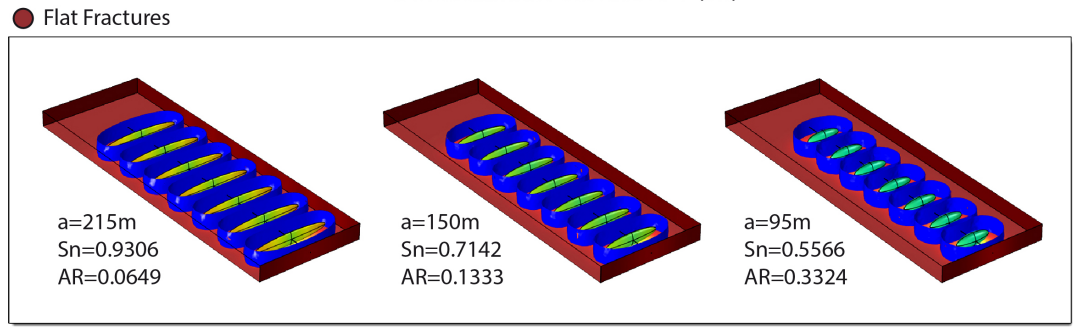

Longitudinal Fractures

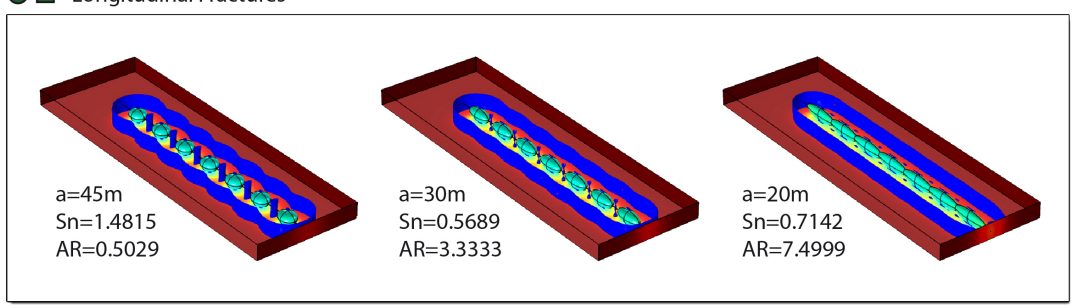

Figure 9. Graphic explanation of the impact of EPV geometry on shale gas production performance. (a) Correlation of Sn and RFn. (b) Snapshots of BCa with pressure state and isosurface of $5 \mathrm{KPa} / \mathrm{m}$ (dark blue surface) after 365 days of simulation. $a$ is the semiaxis of the EPV perpendicular to the well and in the same plane as the SRV. $b$ is the semi-axis of the EPV longitudinal to the well and in the same plane as the SRV.

We indicate that these conclusions are available through the development of a highfidelity numerical model with qualitative and quantitative results adjusted to field data and scientific studies. However, a validation of these results has not been carried out with real data of microseismivity-geometry EPVs vs. Production as this type of data is not public. 


\subsection{Geomechanical and Fracture Mechanics Considerations of Shale Gas Play in the EPVs Shape}

Geometry of the fracture is highly conditioned by two natural phenomena: geomechanics formation and fracturing mechanics.

- Geomechanics. The drilling direction of the well must follow a guideline as parallel as possible to the minor main compression direction. This would be an essential design criterion for achieving flat perpendicular fractures.

- $\quad$ Fracture mechanics. Formations must be as fragile as possible. With equal petrological parameters, the more fragile formations will explode more efficiently, generating a network of fractures that will configure a larger ellipsoidal fractured surface, in addition to generating a higher permeability.

To take full advantage of both properties of the formation, we see the need to carry out technological developments both in the fracturing fluid and in the projectiles that generate the main fracturing planes.

\subsection{Comparative Analysis of Results}

We define a homogeneous metric to be able to draw results about the impact of the studied variables on methane gas production and its economic profitability. Variables we studied refer to physical quantities whose numerical values have very different orders of magnitude. In order to solve this situation, we define a metric that allows analyzing the sensitivity of both RF and IRF to each of the values in a homogeneous way using the Equation (16).

$$
\frac{\Delta \diamond}{\Delta \square}=\log \left[10^{4}\left(\frac{\frac{\left|\vartheta_{f}-\diamond_{i}\right|}{\oslash_{i}}}{\frac{\left|\square_{f}-\square_{i}\right|}{\square_{i}}}\right)\right]=4+\log \left(\frac{\frac{\left|\diamond_{f}-\diamond_{i}\right|}{\oslash_{i}}}{\frac{\left|\square_{f}-\square_{i}\right|}{\square_{i}}}\right)
$$

We make the following considerations in relation to Equation (16):

- $\diamond$ refers to either RF or IRF.

- $\square$ refers to any of the four production parameters: $\phi, \mathrm{k}, \mathrm{S}_{\mathrm{k}}$ or AR.

- Equation (16) establishes a metric that allows a sensitivity analysis of RF and IRF with respect to the four parameters studied.

- The subscript " $\mathrm{f}$ " refers to final and " $\mathrm{i}$ " to initial. Thus, the final and initial data of the simulations carried out in each parametric sweep are referenced.

- We adopt linearity hypothesis in the evolution of RF and IRF.

- In Equation (16) the analysis performed is dimensionless. The fundamental idea of this metric is to establish a way to measure how many units RF or IRF vary for each unit that porosity, permeability, kerogen content or Aspect Ratio vary.

- A feature of the equation that may seem unique is the multiplication of the dimensionless coefficients by $10^{4}$. The reason for doing this is to have mean sensitivity values that are always equal to or greater than 1 .

- The aim of the decimal logarithm is to reduce the size of the magnitudes that would be obtained.

- As a final step, the mean sensitivity metric is normalized to values between 0 and 1 .

- We apply this methodology to results shows in Table 3, and we draw corresponding results in the spider plot, Figure 10.

Table 3. Dimensionless results of sensitivity analysis.

\begin{tabular}{ccccc}
\hline & $\boldsymbol{\phi}$ & $\mathbf{k}$ & $S_{\boldsymbol{k}}$ & AR \\
\hline$\frac{\Delta \mathrm{RF}}{\Delta \square}$ & 0.76 & 1.00 & 0.44 & 0.91 \\
$\frac{\Delta \mathrm{IRF}}{\Delta \square}$ & 0.84 & 1.00 & 0.19 & 0.91 \\
\hline
\end{tabular}




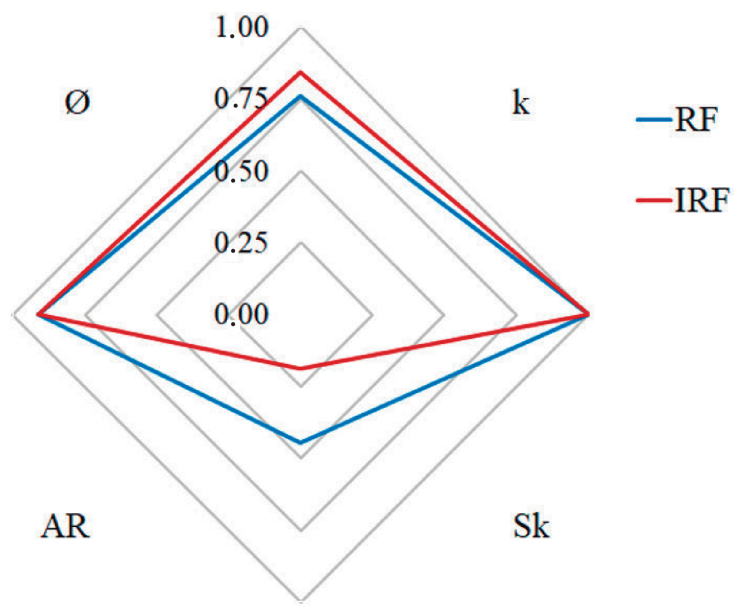

Figure 10. Spider graph representing the sensitivity of the well performance to each variable studied.

We study into more detail the spider chart and we see how both RF and IRF are equally sensitive to variations in both permeability and Aspect Ratio, Figure 10. This is because these two parameters only have an effect on the methane production mechanics, therefore on the EUR and not on the GIP of the formation nor on the CAPEX of the investment in the well. However, we can see how the variation of RF and IRF with respect to porosity and the amount of kerogen differs. This is due to the fact that when sweeping petrological parameters the GIP varies, in addition to the EUR, see Equations (12) and (13).

An interesting and not very intuitive issue is to see how the sensitivity of the IRF is greater than that of the RF when the porosity is varied, whereas when the kerogen content is varied, the opposite situation occurs. This phenomenon is due to the fact that the amount of gas extracted for each unit variation in porosity is proportionally greater than the increase in the gas available in the formation. The opposite situation occurs with the unitary variation in the kerogen. In this case, the amount of gas extracted increases much less than the availability of gas.

We see how the sensitivity of RF and IRF to the variation in porosity is much higher than that of these indicators to the variation of kerogen. This phenomenon is explained because the free gas in pore, given by the porosity, is the dominant fraction in the GIP of the BCa.

To take full advantage of the impact of the EPV in economic performance, we propose as a technological developments to modify on the hydrofracturing fluids and on the projectiles that generate the main fracturing plane. It would be interesting to obtain fluids with characteristics such as adequate density and viscosity to increase the fracturing surface. Moreover, the projectiles used in the generation of the holes in the wells could be increased in power and modifications made to their characteristics and trajectories. This would allow the generation of initial fracture planes as large as possible, with geometries that favor the flatness of the final EPV.

Finally, we note that during the hydrofracturing processes, microseismicity analyses are usually carried out that allow to know the extend of fracturing induction in each phase. An economically interesting aspect of this study is that by analyzing these maps of microseismicity, an approximate idea of the success of hydrofracturing from a geometric point of view can be obtained. In this way, the economic potential of the well can be diagnosed before completing the final phases such as completion, installation of valves or electromechanical systems for the remote control of the well. If the hydrofracturing has had an inefficient geometry, wells could be discarded before carrying out all of these final tasks and incurring greater investment or CAPEX expenses, and even before putting the well into operation and incurring OPEX-type expenses. 


\section{Conclusions}

In this study, we propose to analyze the impact of the geometry of hydrofractured ellipsoidal volumes (EPV) on the economic performance of shale gas wells. To have a metric of this impact, we made a comparison with other parameters of proven relevance (e.g., porosity) reaching the following conclusions:

- The geometry of the EPSv has a determining importance in the economic performance of shale gas wells.

- Gas production efficiency and economic performance take different trends depending on whether petrological or production parameters are varied.

- Geomechanics and fracture mechanics emerge as two disciplines of more relevance than expected in the economic performance of shale gas well production.

- We show that improving porosity the RF decreases considerably, while the IRF increases. Economically, a good investment result is achieved, but a lot of GIP is wasted. In shale gas industry a good economic performance is not synonymous with a good use of available resources.

Author Contributions: Conceptualization, A.S. and L.C.-F.; methodology, A.S.; software, L.C.-F.; validation, R.J., I.C. and L.C.-F.; formal analysis, L.C.-F.; investigation, A.S.; resources, L.C.-F.; data curation, A.S.; writing-original draft preparation, A.S.; writing-review and editing, R.J., I.C. and L.C.-F.; visualization, A.S.; supervision, I.C.; project administration, L.C.-F.; funding acquisition, I.C. All authors have read and agreed to the published version of the manuscript.

Funding: This research has been partially funded by Ministerio de Ciencia, Innovación y Universidades of the Spanish Government (grant RTI2018-093366-B-I00), by the Consellería de Educación e Ordenación Universitaria of the Xunta de Galicia (grant\#ED431C 2018/41) and by the Group of Numerical Methods in Engineering of the Universidade da Coruña.

Institutional Review Board Statement: Not applicable.

Informed Consent Statement: Not applicable.

Data Availability Statement: Not applicable.

Conflicts of Interest: The authors declare no conflict of interest.

\begin{tabular}{|c|c|}
\hline Abbrevi & ions \\
\hline The follor & ing abbreviations are used in this $\mathrm{m}$ \\
\hline EPV & Effective Propped Volume \\
\hline EPVs & Effective Propped Volume (plural) \\
\hline SRV & Stimulated Recovery Volume \\
\hline EUR & Estimated Ultimate Recovery \\
\hline $\mathrm{O} \& \mathrm{G}$ & Oil and Gas \\
\hline $\mathrm{BCa}$ & Base Case \\
\hline GIP & Gas in Place \\
\hline RF & Recovery Factor \\
\hline IRF & Investment Recovery Factor \\
\hline MMBTU & Million of British Thermal Units \\
\hline Mscf & Thousand standard cubic feet \\
\hline MM & Millions \\
\hline ROI & Return on Investment \\
\hline CAPEX & Capital Expenditure \\
\hline OPEX & Operational Expenditures \\
\hline IP & Initial Production \\
\hline AR & Aspect Ratio \\
\hline DC & Decline Curves \\
\hline Sn & Dimensionless Ellipsoidal Surface \\
\hline RFn & Dimensionless Recovery Factor \\
\hline
\end{tabular}




\section{References}

1. Brockway, P.E.; Owen, A.; Brand-Correa, L.I.; Hardt, L. Estimation of global final-stage energy-return- on-investment for fossil fuels with comparison to renewable energy sources. Nat. Energy 2019, 4, 616-621. [CrossRef]

2. Wigley, T.M.L. Coal to gas: The influence of methane leakage. Clim. Chang. 2011, 108, 601-608. [CrossRef]

3. Rodhe, H. A Comparison of the Contribution of Various Gases to the Greenhouse Effect. Science 1990, 248, 1217-1219. [CrossRef] [PubMed]

4. Weijermars, R. US shale gas production outlook based on well roll-out rate scenarios. Appl. Energy 2014, 124, 283-297. [CrossRef]

5. Stephenson, M. Shale Gas and Fracking. The Science Behind the Controversy; Elsevier: Amsterdam, The Netherlands, 2015.

6. Lis, A.; Stankiewicz, P. Framing Shale Gas for Policy-Making in Poland. J. Environ. Pol. Plann. 2016, 19, 53-71. [CrossRef]

7. Sher, C.; Wu, C. Fracking in China: Community Impacts and Public Support of Shale Gas Development. J. Contem. China 2018, 27, 626-641. [CrossRef]

8. Wang, K.; Vredenburg, H.; Wang, T. Liangyong, F. Financial return and energy return on investment analysis of oil sands, shale oil and shale gas operations. J. Clean. Prod. 2019, 223, 826-836. [CrossRef]

9. Kinnaman, T.C. The economic impact of shale gas extraction: A review of existing studies. Ecol. Econ. 2011, 70, 1243-1249. [CrossRef]

10. Bowker, K.A. Barnett Shale gas production, Fort Worth Basin: Issues and discussion. AAPG Bull. 2007, 91, 523-533. [CrossRef]

11. Middleton, R.S.; Gupta, R.; Hyman, J.D.; Viswanathan, H.S. The shale gas revolution: Barriers, sustainability, and emerging opportunities. Appl. Energy 2017, 199, 88-95. [CrossRef]

12. Shah, M.; Shah, S.; Sircar, A. A comprehensive overview on recent developments in refracturing technique for shale gas reservoirs. J. Nat. Gas Sci. Eng. 2017, 46, 350-364. [CrossRef]

13. Li, C.; Chau, V.T.; Xie, H.; Bažant, Z.P. Recent advances in mechanics of fracking and new results on 2D simulation of crack branching in anisotropic gas or oil shale. Acta Mech. 2018, 229, 975-992. [CrossRef]

14. Hattori, G.; Trevelyan, J.; Augarde, C.E. Coombs, W.M.; Aplin, A.C. Numerical Simulation of Fracking in Shale Rocks: Current Stateand Future Approaches. Arch. Comput. Methods Eng. 2017, 24, 281-317. [CrossRef]

15. Scotchman, I.C. Shale gas and fracking: Exploration for unconventional hydrocarbons. Proc. Geol. Assoc. 2016, 127, 535-551. [CrossRef]

16. Chau, V.T.; Bažant Z.P.; Su, Y. Growth model for large branched three-dimensional hydraulic crack system in gas or oil shale. Phil. Trans. R. Soc. A 2016, 374. [CrossRef]

17. Maxwell, S. Microseismic hydraulic fracture imaging: The path toward optimizing shale gas production. Lead. Edge 2011, 30, 340-346. [CrossRef]

18. Tafti, T.A. Characterizing Fracture Network in Shale Reservoir Using Microseismic Data. In Proceedings of the SPE Western Regional Meeting, Bakersfield, CA, USA, 21-23 March 2012; pp. 1-16. [CrossRef]

19. Hou, B.; Chen, M.; Li, Z.; Wang, Y.; Diao, C. Propagation area evaluation of hydraulic fracture networks in shale gas reservoirs. Petrol. Explor. Dev. 2014, 41, 833-838. [CrossRef]

20. Gong, B.; Qin, G.; Towler, B.F. Discrete Modelling of Natural and Hydraulic Fractures in shale-gas reservoir. Presented at the SPE Annual Technical Conference and Exhibition, Denver, CO, USA, 30 October-2 November 2011 [CrossRef]

21. Lai, C.; Rallabandia, B.; Perazzoa, A.; Zhengb, Z.; Smiddyc, S.E.; Stonea, H.A. Foam-driven fracture. Proc. Natl. Acad. Sci. USA 2018, 115, 8082-8086. [CrossRef]

22. Li, S.; Ding, Y.; Cai, B. Modeling Method for Multi-Fractured Horizontal Well in Tight Oil Reservoirs. Proc. Int. Field Explor. Dev. Conf. 2019, 80, 873-883.

23. Cipolla, C.L.; Lolon, E.P.; Erdle, J.C.; Tathed, V. Modeling Well Performance in Shale-Gas Reservoirs. In Proceedings of the SPE, EAGE Annual Conference, Amsterdam, The Netherlands, 18-21 October 2009; pp. 873-883. [CrossRef]

24. Satishchandra D.; Ostebo, P.; Rune, J. Controling Parameters for Shale Gas Production Into a Well-Induced Fracture: A FractureMatrix Modelling Aproach. In Proceedings of the SPE, EAGE Annual Conference, Copenhagen, Denmark, 11-14 June 2018 [CrossRef]

25. Lai, C.-Y.; Zheng, Z.; Dressaire, E.; Wexler, J.; Stone, H.A. Experimental study on penny-shaped fluid-driven cracks in an elastic matrix. Proc. R. Soc. A 2018, 471. [CrossRef]

26. Silin, D.; Kneafsey, T. Shale Gas: Nanometer-Scale Observations and Well Modelling. J. Can. Pet. Technol. 2012, 464-475. [CrossRef]

27. Cipolla, C.L.; Lolon, E.P.; Erdle, J.C. Rubin, B. Reservoir Modeling in Shale-Gas Reservoirs. In Proceedings of the SPE Eastern Regional Meeting, Charleston, WV, USA, 23-25 September 2009; pp. 464-475. [CrossRef]

28. Patzek, T.W.; Male, F.; Marder, M. Gas production in the Barnett Shale obeys a simple scaling theory. Proc. Natl. Acad. Sci. USA 2013, 110, 304-315. [CrossRef]

29. Swami, A.S.V.; Javadpour, F. A Numerical Model for Multi-Mechanism Flow in Shale Gas Reservoirs with Application to Laboratory Scale Testing. In Proceedings of the EAGE Annual Conference \& Exhibition incorporating SPE Europec, London, UK, 10-13 June 2013. [CrossRef]

30. Swami, A.S.V. A Pore Scale Gas Flow Model for Shale Gas Reservoir. In Proceedings of the SPE-Americas Unconventional Resources Conference, Pittsburgh, PA, USA, 5-7 June 2012. [CrossRef]

31. $\mathrm{Xu}, \mathrm{W}$. Modelling Gas Transport in Shale Gas Reservoir-Conservation Laws. In Proceedings of the Unconventional Resources Technology Conference, Denver, CO, USA, 25-27 August 2014. [CrossRef] 
32. Cho, Y.; Apaydin, O.G.; Ozkan, E. Pressure-Depent Natural Fracture Permeability in Shales and its Effect on Shale-Gas Well Production. SPE Res. Eval. Eng. 2013, 16, 216-228. [CrossRef]

33. Singh, H.; Javadpour, F.; Ettehadtavakkol, A.; Darabi, H. Nonempirical Apparent Permeability of Shale. SPE Res. Eval. Eng. 2014, 17, 414-424. [CrossRef]

34. Civan, F.; Rai, C.S.; Sondergeld, C.H. Shale-Gas Permeability and Diffusivity Inferred by Improved Formulation of Relevant Retention and Transport Mechanisms. Transp. Porous Med. 2011, 86, 925-944. [CrossRef]

35. Wu, T.; Zhang, D.; Li, X. A radial differential pressure decay method with micro-plug samples for determining the apparent permeability of shale matrix. J. Nat. Gas Sci. Eng. 2020, 74. [CrossRef]

36. Sakhaee-Pour, A.; Bryant, S.L. Gas Permeability of Shale. Presented at the SPE Annual Technical Conference and Exhibition, Denver, CO, USA, 30 October-2 November 2011. [CrossRef]

37. Davarpanah, A.; Mirshekari, B. Experimental Investigation and Mathematical Modeling of Gas Diffusivity by Carbon Dioxide and Methane Kinetic Adsorption. Ind. Eng. Chem. Res. 2019, 58, 12392-2400. [CrossRef]

38. Hu, X.; Xie, J.; Cai, W.; Wang, R.; Davarpanah, A. Thermodynamic effects of cycling carbon dioxide injectivity in shale reservoirs J. Pet. Sci. Eng. 2020, 195, 1-7. [CrossRef]

39. Soage, M.A. A Numerical Modelling Framework for the Optimization and Economic Analysis of Unconventional Gas Production. Ph.D. Thesis, University of A Coruna, Coruna, Spain, 2021.

40. Wilson, K.C.; Durlofsky, L.J. Optimization of shale gas field development using direct search tecniques and reduce-physics models. J. Petrol. Sci. Eng. 2013, 108, 304-315. [CrossRef]

41. Wilson, K.C. Optimization of Shale Gas Resource Develoment Usign Reduce-Physics Surrogate Model. Master's Thesis, Stanford University, Stanford, CA, USA, 2012.

42. Seales, M.B.; Ertekin, T.; Yilin Wang, J. Recovery Efficiency in Hydraulically Fractured Shale Gas Reservoirs. ASME. J. Energy Resour. Technol. 2017, 139, 042901-1-042901-8. [CrossRef]

43. Han, B.; Bian, X. A hybrid PSO-SVM-based model for determination of oil recovery factor in the low-permeability reservoir. Petroleum 2018, 4, 43-49. [CrossRef]

44. Mahmoud, A.A.; Elkatatny, S.; Chen, W.; Abdulraheem, A. Estimation of Oil Recovery Factor for Water Drive Sandy Reservoirs through Applications of Artificial Intelligence. Energies 2019, 12, 3671. [CrossRef]

45. Clark, A.J. Determination of Recovery Factor in the Bakken Formation, Mountrail County, ND. Presented at the SPE Annual Technical Conference and Exhibition, New Orleans, LA, USA, 4-7 October 2009. [CrossRef]

46. McGlade, C.; Speirs, J.; Sorrell, S. Methods of estimating shale gas resources-Comparison, evaluation and implications. Energy 2013, 59, 116-125. [CrossRef]

47. COMSOL Multiphysics. Introduction to COMSOL Multiphysics; COMSOL Inc.: 2018. Available online: http://www.math.chalmers. se/ torbjrn/M3/IntroductionToCOMSOLMultiphysics.pdf (accessed on 9 March 2021).

48. Freeman, C.M.; Moridis, G.; IIk, D.; Blasingame, T.A. A Numerical Study of Performance for Tight Gas and Shale Gas Reservoir Systems. J. Petro. Sci. Engine. 2013, 108, 22-39. [CrossRef]

49. Song, H.; Yu, M.; Zhu, W.; Wu, P.; Lou, Y.; Wang, Y.; Killough, J. Numerical investigation of gas flow rate in shale gas reservoirs with nanoporous media. Int. J. Heat Mass Transf. 2015, 80, 626-635. [CrossRef]

50. Ikewun P.; Ahmadi, M. Production Optimization and Forecasting of Shale Gas Wells Using Simulation Methods and Decline Curve Analysis. Presented at the SPE Western Regional Meeting, Bakersfield, CA, USA, 21-23 March 2012. [CrossRef]

51. Shabro, V.; Torres-Verdin, C.; Javadpour, F. Numerical Simulation of Shale-Gas Production: From Pore-Scale Modeling of Slip-Flow, Knudsen Diffusion, and Langmuir Desorption to Reservoir Modeling of Compressible Fluid. Presented at the North American Unconventional Gas Conference and Exhibition, The Woodlands, TX, USA, 14-16 June 2011. [CrossRef]

52. Stueck, H.; Houseknecht, D.; Franke, D.; Gautier, D.; Bahr, A.; Ladage, S. Shale-Gas Assessment: Comparison of Gas-In-Place Versus Performance-Based Approaches. Nat. Resour. Res. 2016, 25, 315-329. [CrossRef]

53. Lee, D.S.; Herman, J.D.; Elsworth, D.; Kim, H.T. A Critical Evaluation of Unconventional Gas Recovery from the Marcellus Shale, Northeastern United States. KSCE J. Civ. Eng. 2011, 15, 679-687. [CrossRef]

54. Askenazi, A.; Biscayart, P.; Cáneva, M. Analogía entre la Formación Vaca Muerta y Shale Gas/Oil Plays de EEUU. SPE Argent. Sect. Young Prof. 2013.

55. Vandenbroucke, M.; Largeau, C. Kerogen origin, evolution and structure. Org. Geochem. 2007, 38, 719-833. [CrossRef]

56. Cheng, Y.; Jiang, S.; Zhang, D.; Liu, C. An adsorbed gas estimation model for shale gas reservoirs via statistical learning. Appl. Energy 2017, 197, 327-341. [CrossRef] 